\title{
EFICÁCIA DA PENETRAÇÃO DE GOTAS DE PULVERIZAÇÃO NO ALGODOEIRO EM DIFERENTES ALTURAS DE PLANTAS
}

\author{
PAUlo CESAR BetTINI
}

Engenheiro Agrônomo

Orientador Prof. Dr. CASIMIRO DIAS GADANHA JUNIOR

Dissertação apresentada à Escola Superior de Agricultura "Luiz de Queiroz", Universidade de São Paulo, para obtenção do título de Mestre em Agronomia, Área de Concentração: Máquinas Agrícolas.

PIRACICABA

Estado de São Paulo - Brasil

Agosto - 2005 


\section{ERRATA}

BETTINI, P.C. Eficácia da penetração de gotas de pulverização no algodoeiro em diferentes alturas de plantas. Piracicaba, 2005. 64p. Dissertação (Mestrado em Agronomia) - Escola Superior de Agricultura "Luiz de Queiroz", Universidade de São Paulo.

\begin{tabular}{|c|c|c|c|}
\hline $\begin{array}{l}\text { Página } \\
\text { XIII }\end{array}$ & $\begin{array}{l}\text { Linha } \\
15\end{array}$ & $\begin{array}{l}\text { Onde se lê } \\
\text { interior da planta }\end{array}$ & $\begin{array}{l}\text { Leia-se } \\
\text { dentro da copa da } \\
\text { planta }\end{array}$ \\
\hline XIII & 20 e 21 & $1.735,51$ e $12.241,03 \mathrm{~cm}^{2}$ & desconsiderar os dados \\
\hline$x V$ & 14 & inside the plant & plant canopy \\
\hline $\mathrm{XV}$ & 19 & $1.735,51$ e $12.241,03 \mathrm{~cm}^{2}$ & desconsiderar os dados \\
\hline 5 & 20 & $\begin{array}{l}\text { Colletotrichum gossypii } \\
\text { (Ramulose) }\end{array}$ & $\begin{array}{l}\text { Colletotrichum gossypii } \\
\text { var. cephalosporioides } \\
\text { (Ramulose) }\end{array}$ \\
\hline 6 & 17 & Murchamento avermelhado - $V$ & $\begin{array}{l}\text { Murchamento } \\
\text { avermelhado }\end{array}$ \\
\hline 38 & 3 & item 4.1 Área foliar das plantas & $\begin{array}{l}\text { desconsiderar os } \\
\text { resultados de áreas } \\
\text { foliares }\end{array}$ \\
\hline
\end{tabular}


Dados Internacionais de Catalogação na Publicação (CIP) DIVISÃO DE BIBLIOTECA E DOCUMENTAÇĀO - ESALQ/USP

\section{Bettini, Paulo Cesar}

Eficácia da penetração de gotas de pulverização no algodoeiro em diferentes alturas de plantas / Paulo Cesar Bettini. - - Piracicaba, 2005.

64 p. : il.

Dissertação (Mestrado) - - Escola Superior de Agricultura Luiz de Queiroz, 2005. Bibliografia.

1. Aplicação controlada de gotículas 2. Algodão 3. Entomologia agrícola 4. Máquina agricola 5. Produto fitossanitário 6 . Pulverização I. Título

CDD 633.51

"Permitida a copia total ou parcial deste documento, desde que citada a fonte - 0 autor" 
A Carlos e Geralda, meus pais

Pelo amor, afeto e carinho

A Carlinhos, Gustavo e Renata, meus irmãos

Pela amizade e espírito de família

A Cris, minha noiva

Pela paciência, amor e compreensão

OFEREÇO

Carlos Bettini, meu pai

DEDICO 


\section{AGRADECIMENTOS}

Ao professor Dr. Casimiro Dias Gadanha Júnior da ESALQ/ USP, pela orientação na execução desta pesquisa;

Ao pesquisador Dr. Hamilton Humberto Ramos do Centro de Engenharia e Automoção do Instituto Agronômico, pela amizade, confiança, incentivo de ingresso na pesquisa e co-orientação na execução desta pesquisa;

Aos pesquisadores e técnicos do Centro de Engenharia e Automação do Instituto Agronômico, pela colaboração e incentivo científico para a execução deste trabalho, com especiais referências à pesquisadora $\mathrm{Dr}^{\mathrm{a}}$. Ila Maria Corrêa e a Srt ${ }^{a}$. Neuza Alves da Silva;

Aos professores do Departamento de Engenharia, Área de Concentração, Máquinas Agrícolas da ESALQ/USP, pelos ensinamentos transmitidos;

À Coordenação de Aperfeiçoamento Pessoal de Nível Superior (CAPES), pela bolsa de estudos concedida durante parte do tempo de realização do curso; 
Aos professores do Departamento de Produção Vegetal da ESALQ/USP, pelos ensinamentos e dicas, em especial ao Professor Dr. Ederaldo José Chiavegato; Ao cotonicultor Tadashi Mine proprietário da Fazenda Xingu, Ituverava - SP, onde foram conduzidos os ensaios, pelo apoio na realização deste trabalho e a seu irmão Kenjiro Mine colaborando e acreditando em trabalhos como este;

A todos que, de alguma forma contribuíram para a realização deste trabalho. 


\section{SUMÁRIO}

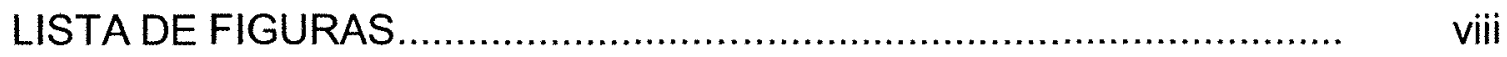

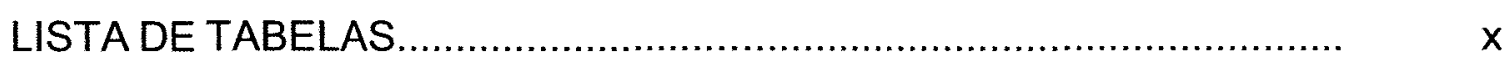

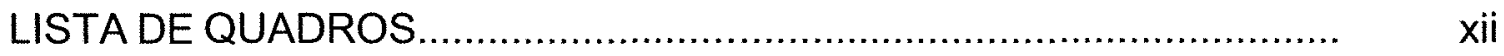

RESUMO ................................................................................

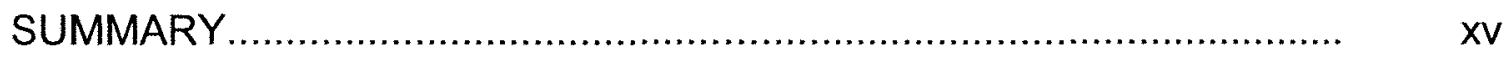

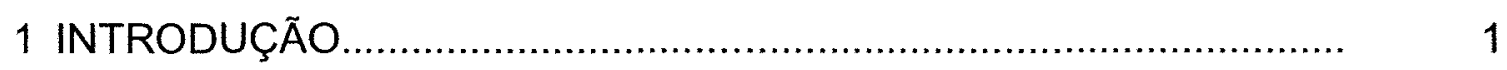

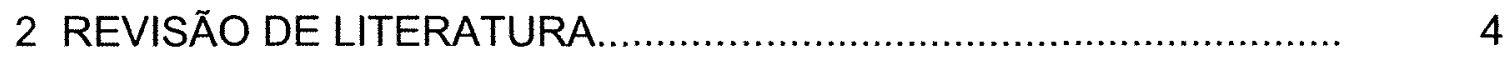

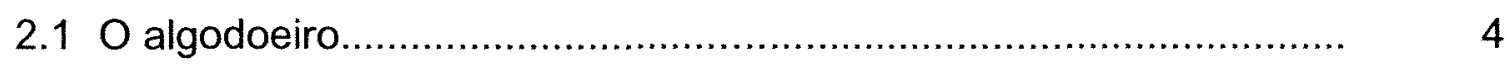

2.2 A tecnologia de aplicação de produtos fitossanitários...................... 5

2.3 Importância do tamanho de gotas ............................................ 10

2.4 Emprego de papéis hidrossensíveis no estudo de gotas de pulverização.

3 MATERIAL E MÉTODOS .......................................................... 18

3.1 Características do campo experimental....................................... 18

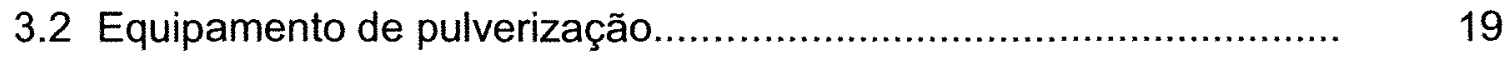

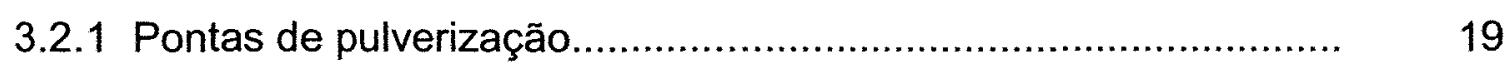

3.2.2 Certificação dos valores de DMV's fornecidos pelo fabricante....... 20

3.2.3.1 Características do pulverizador............................................... 24 
3.2.3.2 Velocidade de trabalho......................................................... 24

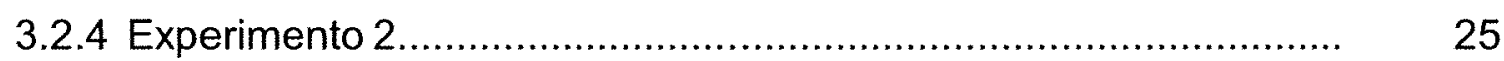

3.2.4.1 Características do pulverizador ..................................... 25

3.2.4.2 Velocidade de trabalho.......................................................... 26

3.3 Coleta e preparação das amostras para determinação do tamanho das gotas.

3.3.1 Desenvolvimento de suportes para fixação dos amostradores.... $\quad 27$

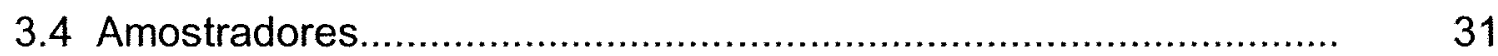

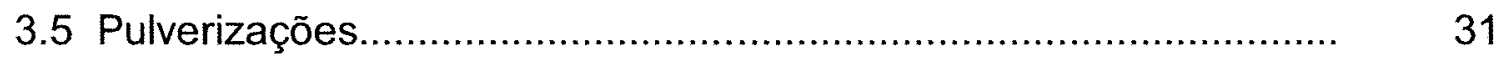

3.6 Coleta e processamento das amostras...................................... 32

3.6.1 Coleta dos papéis hidrossensiveis......................................... 32

3.6.2 Aquisição das imagens dos papéis hidrossensiveis..................... 32

3.6.3 Resolução em pixels adotada para análise das gotas................. 32

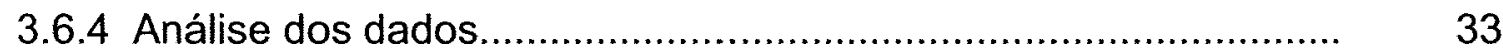

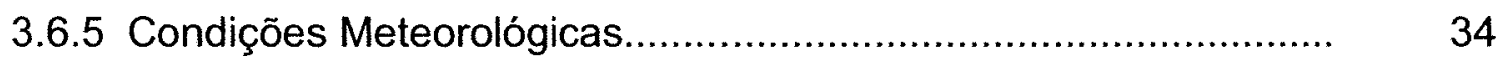

3.6.6 Determinação do Índice de Área Foliar (IAF)............................ 35

4 RESULTADOS E DISCUSSÃO.................................................... 38

4.1 Área foliar das plantas.......................................................... 38

4.2 Avaliação do tamanho de gotas....................................................

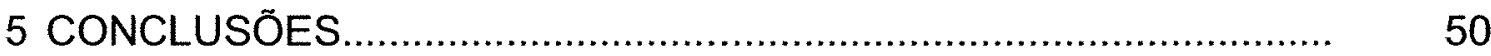

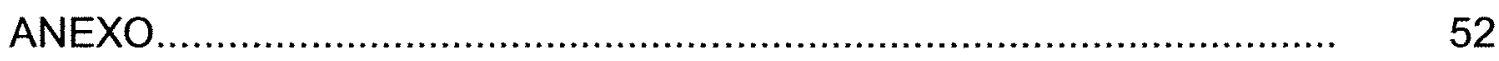

REFERÊNCIAS BIBLIOGRÁFICAS.............................................. 55 


\section{LISTA DE FIGURAS}

Página

$1 \quad$ Plantas alvo dos experimentos 1 (A) e 2 (B) na lavoura comercial de algodão da Fazenda Xingu em Ituverava, SP.

2 Sistema para limitação do número de gotas da pulverização coletadas sobre papel hidrossensível, evidenciando $O$ restritor da pulverização aberto $(A)$ e fechado $(B)$

3 Posicionamento dos suportes (A) e lâminas de alumínio (B), desenvolvidos para melhor acondicionar os papéis hidrossensiveis durante as amostragens de gotas no interior da cultura do algodoeiro.

$4 \quad$ Suporte e amostradores desenvolvidos para acondicionar os papéis hidrossensiveis durante as amostragens de gotas no interior da cultura do algodoeiro, evidenciando a regulagem de altura e movimentação lateral.

5 Croqui da área experimental evidenciando as linhas de semeadura (L1... L12), o caminhamento do rodado do equipamento de pulverização $\left({ }^{\wedge}\right)$ e as repetições (R1... R4), compostas por 6 plantas selecionadas (Ituverava,-SP, 2004)

6 Área experimental, com os suportes de amostragem devidamente dispostos para amostragem, nas plantas alvo selecionadas (Ituverava-SP, 2004).

$7 \quad$ Exemplo de papel hidrossensível digitalizado e utilizado para avaliação de tamanho de gota.

8 Planta identificada pronta para ser embalada e encaminhada para medição de área foliar (Ituverava-SP, 2004)... 
9 Sistema utilizado na digitalização das folhas para cálculo do índice de área foliar evidenciando a separação dos ramos das folhas em plantas alvo (A), o cuidado em não danificar as folhas (B) a digitalização das mesmas (C) ............................ 


\section{LISTA DE TABELAS}

Página

1 Importância de doenças do algodoeiro, nas principais regiões produtoras do Brasil em 1999

2 Classificação da pulverização segundo tamanho das

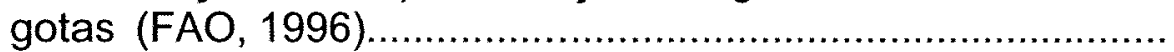

3 Pontas de referência para classificação da pulverização (FAO, 1998)

4 Arranjo de pontas para avaliação da eficácia da penetração de gotas de pulverização na copa do algodoeiro em diferentes fases vegetativas. (Ituverava-SP, 2004)

Características da pulverização realizada na cultura do algodoeiro, com $0,80 \mathrm{~m}$ de altura, para análise do espectro de gotas atingindo diferentes posições da planta. (ItuveravaSP, 2004)

6 Características da pulverização realizada na cultura do algodoeiro, com 1,00 m de altura, para análise do espectro de gotas atingindo diferentes posições da planta. (ItuveravaSP, 2004)

$7 \quad$ Área foliar das plantas de algodoeiro aos $54 \mathrm{DAE}$, com altura de $0,80 \mathrm{~m}$, utilizadas como alvo na avaliação da penetração das gotas de pulverização. (Ituverava-SP, 2004)...

8 Área foliar das plantas de algodoeiro aos $90 \mathrm{DAE}$, com altura de $1,00 \mathrm{~m}$, utilizadas como alvo na avaliação da penetração das gotas de pulverização (Ituverava-SP, 2004) 
$9 \quad$ Teste de Tukey ao nivel de $5 \%$ de probabilidade aplicado às médias da interação diâmetro produzido $x$ diâmetro coletado, para a página superior da folha de plantas de algodoeiro com $0,80 \mathrm{~m}$. (Ituverava-SP, 2004).................................................

10 Teste de Tukey ao nível de $5 \%$ de probabilidade aplicado às médias da interação posição na planta $x$ diâmetro coletado, para a página superior da folha de plantas de algodoeiro com 0,80 m (Ituverava-SP, 2004)

11 Teste de Tukey ao nível de $5 \%$ de probabilidade aplicado às médias da interação diâmetro produzido $x$ diâmetro coletado, para a página superior da folha de para plantas de algodoeiro com 1,00 m (Ituverava-SP, 2004)

12 Teste de Tukey ao nível de $5 \%$ de probabilidade aplicado às médias da interação posição na planta $x$ diâmetro coletado, para a página superior da folha de plantas de algodoeiro com 1,00 m (Ituverava-SP, 2004) 


\section{LISTA DE QUADROS}

Página

1 Principais pragas causadoras de danos econômicos durante o ciclo de produção do algodoeiro (EMBRAPA, 2005)..............

2 Análise dos diâmetros de gotas fornecidos pelo fabricante comparados aos diâmetros obtidos no software E-sprinkle e no analisador laser. 


\title{
EFICÁCIA DA PENETRAÇÃO DE GOTAS DE PULVERIZAÇÃO NO ALGODOEIRO EM DIFERENTES ALTURAS DE PLANTAS
}

\author{
Autor: PAULO CESAR BETTINI \\ Orientador: Prof. CASIMIRO DIAS GADANHA JUNIOR
}

\section{RESUMO}

Embora a pulverização seja o principal método utilizado para o tratamento fitossanitário da cultura do algodoeiro, esta tem sido realizada de maneira empírica, o que evidencia a necessidade de trabalhos para avaliar a penetração de gotas no algodoeiro, uma vez que algumas de suas principais pragas e doenças ocorrem no interior da planta. Assim, o presente trabalho teve como objetivo principal avaliar a eficácia da penetração de gotas de pulverização no algodoeiro, em diferentes fases vegetativas. Para isso, pulverizadores equipados com pontas produzindo 5 diferentes espectros de gotas $(200,243,297,358$ e $396 \mu \mathrm{m})$ pulverizaram sobre plantas de algodoeiro, em duas diferentes fases vegetativas $\left(0,80 \mathrm{~m}\right.$ de altura com $1.735,51 \mathrm{~cm}^{2}$ de área foliar e $1,0 \mathrm{~m}$ de altura com $12.241,03 \mathrm{~cm}^{2}$ de área foliar), equipadas com hastes coletoras contendo cada uma 3 placas de alumínio, simulando a folha da cultura, com um papel hidrossensivel na parte superior e outro na inferior, posicionadas no terço superior, médio e inferior da planta. Foram realizadas 4 repetições, cada uma composta por 6 plantas selecionadas ao longo da barra 
do pulverizador. Uma avaliação visual prévia dos resultados mostrou que nenhum dos tratamentos utilizados foi eficiente em colocar uma quantidade adequada de gotas sobre os papéis hidrossensiveis posicionados na parte inferior dos amostradores, razão pela qual os mesmos não foram considerados na análise. $O$ espectro das gotas coletadas foi determinado por meio do programa computacional e-Sprinkle, versão 2004, desenvolvido pela Embrapa/Ablevision. Foram utilizados os dados relativos ao número de gotas por classe de tamanho, e não o diâmetro mediano volumétrico, uma vez que a eficácia de várias gotas pequenas em atingir o alvo poderia ser mascarada por apenas uma gota média ou grande caso este último fosse utilizado. Uma vez normalizados, os dados foram analizados para cada época segundo um delineamento inteiramente casualizado, dentro de um esquema fatorial $5 \times 3 \times 17$, correspondendo a 5 diâmetros iniciais, 3 posições na planta e 17 classes de diâmetros verificados sobre os amostradores. Pelos resultados obtidos nas condições dos ensaios, para as duas épocas analisadas, pode-se concluir que gotas com diâmetros na faixa de 95 a $174 \mu \mathrm{m}$ proporcionaram melhor distribuição no perfil da planta do algodoeiro; em pulverizações onde o alvo é o terço médio e superior da planta, gotas de até $363 \mu \mathrm{m}$ mostraram-se eficientes; gotas com diâmetro superior a $500 \mu \mathrm{m}$, em função da baixa penetração não devem ser utilizadas no tratamento fitossanitário do algodoeiro. Estudos complementares de cobertura e deposição de calda, com gotas dentro destas faixas de diâmetros, necessárias a eficácia do controle das principais pragas do algodoeiro, são ainda necessários. 


\title{
EFFECTIVENESS OF THE PENETRATION OF DROPS OF SPRAYING IN THE COTTON PLANT IN DIFFERENT HEIGHTS OF PLANTS
}

\author{
Author: PAULO CESAR BETTINI \\ Adviser: Prof. CASIMIRO DIAS GADANHA JUNIOR
}

\section{SUMMARY}

Although the spraying is the main method used for cotton plant crop protection, it has been carried through in an empirical way, that evidences the necessity of studies to evaluate the penetration of the drops into the cotton plant, once some of its main plagues and illnesses occur inside the plant. Thus, the present study aimed to evaluate the effectiveness of drop penetration sprayed in the cotton plant in different vegetative phases. For that reason, sprayers equipped with nozzle 5 different droplet spectrum $(200,243,297,358$ and $396 \mu \mathrm{m})$ have sprayed on cotton plants, in two different vegetative phases $(0,80 \mathrm{~m}$ of height with $1.735 .51 \mathrm{~cm}^{2}$ of foliar area and $1,0 \mathrm{~m}$ of height with $12.241,03 \mathrm{~cm}^{2}$ of foliar area), equipped with samplers rods containing 3 aluminum plates each, simulating the plant leaf, with a water sensitive paper on its both sides. It was considered 4 repetitions, each one composed by 6 plants selected along the sprayer bar. A previous visual evaluation of the results showed that none of the treatments used was efficient in placing an adequate amount of droplets on the water sensitive paper that was located in the lower part of the leaf. Because of 
that, this lower side analysis was not considered. The specter of the collected drops was determined through the software ware e-Sprinkle, version 2004, developed by Embrapa/Ablevision. Data related to the number of droplets by size group were used instead of the volume median diameter. The reason for that is because the effectiveness of a great number of small droplets reaching the target could be masked by only one big or median drop. Once the data had been normalized, they were analyzed concerning each phase, according to an entirely casual delineation, in a factorial project $5 \times 3 \times 17$, corresponding to the 5 initial diameters, 3 positions in plant and 17 diameter groups verified on the collectors. The results, which were obtained in the condition of both phases analyzed, showed that drops with about 95 to $174 \mu \mathrm{m}$ diameter provided a better distribution in the cotton plant profile; in sprayings where the target is the third medium and superior parts of the plant, droplets lower than $363 \mu \mathrm{m}$ were efficient; droplets with a diameter bigger than $500 \mu \mathrm{m}$ are not usefull in the cotton plant crop protection treatment, because of the low penetration function. Complementary studies of coverage and deposition of the chemicals, with droplets this range of in diameters, which are necessary to the effectiveness of cotton plant main plague control, are still needed. 


\section{INTRODUÇÃO}

O algodão brasileiro tem alta qualidade e ocupa uma área de aproximadamente 1,15 milhões de hectares (Brasil, 2005), cultivados nas regiões, norte, nordeste, sudeste, sul e centro oeste, que possuem cerca de $55 \%$ da área e produzem 1,38 milhões de toneladas de algodão em caroço, o que representa $62 \%$ do algodão produzido no pais (Brasil, 2005). A produção brasileira é responsável pela quase totalidade do abastecimento da indústria têxtil do país, e como exemplo, no ano de $1995,74,3 \%$ da necessidade têxtil paulista e $39,6 \%$ da necessidade da indústria cearense eram supridos pela produção nacional. Em 2000, estas porcentagens evoluíram para 91,1\% e $70,9 \%$ respectivamente, sendo o Estado do Mato Grosso o maior produtor (FNP, 2002). Assim, a cultura do algodão apresenta grande importância sócioeconômica para o país, e considerando o grande potencial de crescimento que a cultura possui no cerrado, será inevitável o aumento na exportação brasileira nas próximas safras (Ornellas et al., 2001).

Analisando a importância econômica e social da cotonicultura, verifica-se que este setor de produção é afetado por grandes problemas fitossanitários. Ataques de pragas chegam a causar perdas substanciais na quantidade e na qualidade da produção. Para seu controle, o agricultor tem utilizado um número elevado de aplicações de produtos químicos (Gondim, 1999), principalmente através da pulverização. Entretanto, mesmo com a evolução dos produtos fitossanitários, cada vez mais eficazes e menos tóxicos, e a fabricação de novas máquinas aplicadoras, as técnicas de aplicação encontram-se num patamar muito aquém do desejado (Carvalho \& Furlani 
Júnior, 1997). Alguns profissionais observam que dentre as operações agrícolas, a pulverização está entre as que apresentam maiores desperdícios (Pio, 2003). No algodão, onde os custos de produção variam de $1.471,98$ a 1.657,20 dólares por hectare, os investimentos em produtos fitossanitários são significativos, variando de 472,25 a 557,94 dólares por hectare (FNP, 2005).

Para realizar uma boa pulverização, deve-se conhecer muito bem o alvo a ser atingido (praga, doença, parte da planta a receber o produto), o produto a ser utilizado, a máquina, o momento da aplicação e as condições ambientais, fatores estes que interagem para proporcionar a eficácia do tratamento fitossanitário (Ramos \& Pio, 2000). Não basta conhecer a dose do produto aplicado por hectare, é importante quantificar o produto que chega às partes da planta onde está o alvo a ser atingido. O pulgão do algodoeiro, por exemplo, é facilmente encontrado sob a folha e por toda a planta, dessa forma, é importante uma boa distribuição do produto por toda a planta, principalmente quando se utiliza produto de ação local (sem redistribuição na planta). $O$ desconhecimento destes princípios básicos faz com que o agricultor, ou o técnico, trabalhe apenas com o volume na busca da maior eficácia das aplicações, o que leva a perdas, como o escorrimento da calda pulverizada. A boa distribuição do produto aplicado e a definição do tamanho de gotas adequado são fundamentais para se obter eficácia nas pulverizações.

Atualmente não existem muitas informações na bibliografia a respeito do espectro de gotas adequado para pulverizações no algodoeiro. No entanto, sabe-se que as folhas agem como um filtro, protegendo $o$ alvo $e$ dificultando a penetração das gotas na cultura (Matthews, 1999). Este filtro é variável com a arquitetura da planta, com a área foliar e estádio de desenvolvimento da cultura. Trabalhos realizados nessa linha em outras culturas comprovam que gotas muito grandes e/ou muito pequenas tem baixa eficiência na penetração (Matthews, 1999; Ramos, 2001; Saab, 1996). 
Pelo exposto, as pulverizações no algodoeiro tem sido feitas de maneira empírica, o que evidencia a necessidade de trabalhos que avaliem a penetração de gotas na copa, uma vez que algumas das principais pragas e doenças desta cultura ocorrem no interior da planta. Assim, o presente trabalho tem como objetivo principal avaliar a eficácia da penetração de diferentes tamanhos de gotas de pulverização na copa do algodoeiro, em diferentes alturas da planta. 


\section{REVISÃO DE LITERATURA}

\subsection{O Algodoeiro}

O algodoeiro herbáceo (gossypium hirsutum L. var. Latifolium Hutch.) é uma planta de origem tropical e subtropical que prefere dias ensolarados, com menos de $30 \%$ de nebulosidade, temperatura média do ar acima de $20^{\circ} \mathrm{C}$, umidade relativa do ar média em torno de $60 \%$ e precipitações bem distribuídas entre 500 e 1800 mm (Beltrão et al., 1999). Esta planta é um dos fotossistemas mais complexos já criado pela natureza (Oosterhihuis, 1999), uma vez que ao longo do ciclo da cultura vários eventos, como crescimento vegetativo, surgimento de gemas reprodutivas, florescimento, desenvolvimento e maturação dos frutos ocorrem ao mesmo tempo, (Rosolem, 2001).

A produção do algodoeiro, assim como tamanho dos frutos e as suas caracteristicas agronômicas, dependem da localização considerada na planta. Cerca de $80 \%$ da produção do algodão encontra-se no terço inferior e mediano da planta (Soares, 1999), que coincide com a região de melhores pesos de sementes e tamanho de capulho (Beltrão et al., 1992, 1993; Soares, 1999). A influência do ambiente na produção do algodão é esperada em função da enorme variação de localidades e anos de semeadura, influência esta relacionada às condições edafoclimáticas regionais além de outros fatores como pragas, doenças, nematóides, deficiências nutricionais, condições meteorológicas e técnicas de cultivo (Chiavegato,1995). 


\subsection{A tecnologia de aplicação de produtos fitossanitários}

Muitas pulverizações precisam ser realizadas no decorrer do ciclo da cultura tais como a aplicação no controle de pragas, doenças, plantas daninhas, além de desfolhantes e maturadores. No algodoeiro, do período de desenvolvimento do botão floral à maturação, ocorre o aumento da altura da planta e da área foliar, afetando significativamente a distribuição das gotas de pulverização. Como as folhas tendem a ser orientadas principalmente na horizontal, elas agem como um filtro eficiente para as gotas grossas e, por conseqüência, a pulverização tende a ser depositada preferencialmente nas superficies das folhas superiores. Isto significa que qualquer praga (inseto ou doença) localizada na superfície inferior de folhas, ou abaixo do terço mediano da planta, é protegido da ação direta de produtos fitossanitários (Matthews, 1999; Summer, 2000). Bouse \& Carlton (1985) em trabalho de medição de gotas com e sem a adição de óleo de soja e de algodão na calda de pulverização, salientam que somente uma pequena fração do volume de calda e/ou de gotas de pulverização (12,5 \% ou menos) consegue penetrar e se depositar no interior de plantas. Tal fato pode justificar as observações de que a ocorrência de algumas das doenças mais comuns da cultura, como Colletotrichum gossypii (Ramulose), Ramularia areola ou Ramularia Gossypii (Mancha de Ramulária), Alternaria Macrospora e Alternaria tenues (Mancha de Alternária) (Kirkpatrick, 2001), que se distribuem por toda a planta, vêm se elevando ano após anos nas principais regiões produtoras (Chiavegato, 2001).

De acordo com Chiavegato (2001), cotononicultores enfrentam grandes danos provenientes de doenças no algodoeiro, como a ramulária, até o momento tida como de ocorrência desconsiderável em tradicionais regiões produtoras de algodão e Região Centro Oeste. Entretanto, Cia \& Fuzatto (1999) já enfatizavam que a ramulose destaca-se como a de maior importância dentre todas as doenças ocorridas, principalmente no cerrado do Brasil. 
As principais doenças da cultura com a respectiva importância por região de produção, segundo Chiavegato (2001), podem ser visualizadas na Tabela 1.

Tabela 1. Importância de doenças do algodoeiro, nas principais regiões produtoras do Brasil em 1999.

\begin{tabular}{lccccccc}
\hline Doença & \multicolumn{7}{c}{ Estados Produtores } \\
& PR & SP & MG & GO & MT & MS & TOTAL \\
F(fungo) B (bactéria) V (vírus) & \multicolumn{7}{c}{ Grau de Importância (") } \\
\hline Murcha de Fusarium - F & 4 & 5 & 3 & 3 & 1 & 2 & 18 \\
Murcha de Verticillium - F & 3 & 3 & 1 & 1 & 1 & 1 & 10 \\
Mancha Angular - B & 4 & 3 & 3 & 3 & 3 & 3 & 19 \\
Outras manchas foliares & 3 & 2 & 2 & 3 & 4 & 3 & 17 \\
Ramulose - F & 3 & 3 & 4 & 5 & 5 & 4 & 24 \\
Nematóides & 4 & 5 & 4 & 3 & 2 & 2 & 20 \\
Doença Azul - V & 4 & 5 & 5 & 5 & 5 & 5 & 29 \\
Murchamento avermelhado - V & 4 & 5 & 3 & 3 & 3 & 3 & 21 \\
\hline
\end{tabular}

Fonte: Chiavegato ${ }^{1}$ citado por Monteiro (2002).

(1) 1 - sem sintomas; 2 - pequena importância; 3 - medianamente importante, necessidade de precauções e estudos; 4 - importante, demandando de medidas de controle; 5 - muito importante, inviabilizando a cultura se não houver controle.

Além das doenças, durante o ciclo da cultura do algodoeiro ocorrem também várias pragas, que se alimentam de folhas, estruturas reprodutivas ou sugam a seiva da planta (Quadro 1), constituindo-se em fatores limitantes para a produção caso medidas eficazes de controle não sejam efetivamente realizadas.

\footnotetext{
${ }^{1}$ CHIAVEGATO, E.J. Importância potencial de doenças do algodoeiro nas regiōes produtoras do Brasil. Apresentado ao 3. Congresso Brasileiro de Algodão, Campo Grande, 2001.
} 


\begin{tabular}{|l|l|}
\hline Nome científico & Nome comum \\
\hline Eutinobothrus brasiliensis e conotrachellus denieri & Brocas \\
Agrotis spp. & Lagarta Rosca \\
Aphis gossypii & Pulgão \\
Frankliniella spp. & Tripes \\
Alabama argillacea & Lagarta Curuquerê \\
Anthonomus grandis & Bicudo \\
Heliothis virescens & Lagarta das Maçãs \\
S.frugiperda e S. eridania & gênero Spodoptera \\
Pectinophora gossypiella & Lagarta Rosada \\
Tetranychus urticae, Polyphagotarsonemus latus & Ácaros \\
Horcias nobilellus e Dysdercus spp. & Percevejos \\
Bemisia tabaci & Mosca Branca \\
\hline
\end{tabular}

Quadro 1 - Principais pragas causadoras de danos econômicos durante o ciclo de produção do algodoeiro (EMBRAPA, 2005).

Dentre as pragas que atacam o algodoeiro o Aphis gossypii (Pulgão), além de ser encontrado distribuído por toda a planta, se localiza na face inferior das folhas, ocorrendo durante todo ciclo de desenvolvimento da cultura. Os pulgões sugam a seiva da planta e em altas e frequentes pressões podem reduzir em até $24,09 \%$ a produção, expressa em peso de algodão em caroço (Vendramin \& Nakano, 1981). Além disso, são vetores de doenças de vírus, como a virose mosaico das nervuras (VMN), constituindo-se em um dos principais problemas da cultura quando em cultivares suscetíveis. Plantas infectadas pela doença podem apresentar redução do número e peso de capulhos por volta de 48,5 a 78,7\% (Santos, 2003).

O Anthonomus grandis (Bicudo do algodoeiro) é outra das principais pragas do algodão herbáceo (Gossypium hirsutum L. raça latifolium Hutch.) e arbóreo (Gossypium hirsutum L. raça Marie Galante Hutch.). Seus danos são provocados principalmente nos botões florais (Lloyd et al., 1961; Ramalho \& Jesus, 1988) e o principal método de controle é o químico. Por fim, podem ser citadas ainda como importantes a Heliothis virescens (Lagarta da Maçã), encontrada nos botões florais situados no terço superior e mediano da 
planta, a Pectinophora gossypiella (Lagarta Rosada) localizada principalmente nas flores e a Spodoptera spp (Gênero Spodoptera) localizada principalmente no terço médio e inferior da planta. Dessa forma, assim como para doenças, a penetração das gotas de pulverização é importante também no controle de algumas das principais pragas da cultura do algodoeiro.

De acordo com Matthews (1999), as folhas agem como um filtro, dificultando a penetração das gotas na cultura, filtro este que varia com o enfolhamento e estádio de desenvolvimento da cultura. Realizando-se um paralelo entre as gotas de pulverização e a radiação e fotossíntese líquida estudada por Barni \& Bergamaschi (1981), nos primeiros estádios da cultura, a área foliar é pequena, com grandes perdas de radiação que atinge diretamente o solo. Com o desenvolvimento da cultura e, por conseguinte, da área foliar, a interceptação da radiação atingirá o máximo, sem haver ainda problemas de sombreamento das áreas inferiores. A partir desse ponto, quando começa a ocorrer o autosombreamento, as folhas inferiores tornam-se deficitárias em termos de fotossíntese líquida. Assim como o aumento da área foliar, reduz apenetração de radiação, ele dificulta também a penetração de gotas na pulverização. Dessa forma, a análise do indice de área foliar (IAF), que relaciona a área de folhas das plantas existentes numa determinada área de solo, torna-se importante também nos trabalhos de tecnologia de aplicação como forma de caracterizar a dificuldade da pulverização penetrar no perfil da cultura.

A variação do IAF pode ocorrer devido a fatores que interferem no arranjo espacial das plantas, como altura de planta, manejo da cultura, fertilidade do solo, máquinas utilizadas, além de outros (Bolonhezi, 1999). Em estudos realizados por Heitholt (1994), onde analisou-se populações de 10 plantas. $\mathrm{m}^{-2}$ de algodão em espaçamento de $0,75 \mathrm{~m}$, observou-se que o IAF deve ser 3,5, para proporcionar maiores rendimentos do algodoeiro. No entanto, 
em espaçamentos convencionais o índice deve ser próximo de 4 (Heitholt et al., 1992; Heitholt, 1994).

A grande maioria das aplicações de produtos fitossanitários é feita por meio de pulverizações, ou seja, pela geração de partículas líquidas onde a divisão do líquido em pequenas gotas ocorre nas pontas de pulverização. As pontas podem ser consideradas como os componentes mais importantes dos pulverizadores hidráulicos, por determinarem as características da pulverização emitida. Existe no mercado uma diversidade de pontas hidráulicas, com diferentes características técnicas e operacionais (Cunha \& Teixeira, 2003). Da correta seleção da ponta de pulverização depende a penetração e a fixação da calda na cultura, e como conseqüência, a eficácia do controle químico (Matuo et al, 2003).

Segundo Matthews (1992) as pulverizações apresentam espectro com grande número de gotas que, na maioria das vezes, possuem diâmetro inferior a $500 \mu \mathrm{m}$. O tamanho de gotas, massa ou volume obtido por intermédio do diâmetro, tem grande importância para os produtos fitossanitários, tanto com relação à eficácia de aplicação como no sentido de reduzir os riscos de contaminação ambiental. A tendência atual é de aplicações com volumes e diâmetros menores, buscando-se maior cobertura e penetração na folhagem. Entretanto, ao se reduzir o diâmetro, eleva-se a interferência dos fatores ambientais, tais como vento, temperatura e umidade relativa, podendo-se elevar as perdas por evaporação e deriva. Neste sentido, apesar de serem eficientes, gotas com diâmetros inferiores a $100 \mu \mathrm{m}$ devem ser evitadas (Reichard et al., 1992). Mesmo assim, a maioria das pontas usadas na aplicação de produtos fitossanitários produzem grande quantidade do volume de pulverização com gotas próximas de $70 \mu \mathrm{m}$ de diâmetro (Zhu et al., 1994).

Entendendo que o produto que realmente controla a praga é aquele que atinge o alvo e não o aplicado, percebe-se que quanto menor a 
diferença entre o volume na ponta de pulverização e sobre o alvo, menor o custo dos tratamentos fitossanitários (Ramos, 2003).

\subsection{Importância do tamanho de gotas}

Uma ponta hidráulica de pulverização produz diferentes tamanhos de gotas, assim, o parâmetro mais usado para a verificação do diâmetro de gotas é o diâmetro mediano volumétrico (DMV), que representa o diâmetro de gota e que divide o volume pulverizado em duas partes iguais. Este valor é sempre próximo das classes superiores das gotas amostradas, uma vez que poucas gotas grandes têm uma enorme influência no total do volume coletado (Carvalho \& Furlani Junior, 1997; Matthews, 1975). Vale lembrar que os dados de tamanho de gotas são expressos em micrometros $(\mu \mathrm{m})$, que representa a milésima parte do milímetro.

A gota ideal para a agricultura é aquela que proporcione o máximo de deposição de produto no alvo, com o mínimo de contaminação do ambiente (Himel, 1969; Himel \& More, 1969). A má seleção pode proporcionar perdas para o solo (endoderiva), como a ocasionada pelo escorrimento de gotas grandes, ou para áreas distantes pela ação do vento (exoderiva), como ocorre com gotas pequenas (Matthews, 1992; Ramos, 2001). Chaim et al., (1999) mostraram que, para a cultura do tomate, a má seleção das gotas tem proporcionado desperdícios superiores a um terço do produto aplicado.

Algumas pessoas acreditam, erroneamente, que aumentar 0 volume de água e aumentar a pressão sobre o líquido até a formação de gotas pequenas, proporcionaria uma melhor eficiência ou melhor distribuição de produtos fitossanitários. A formação de gotas muito pequenas, ou da "névoa", resulta na falsa impressão visual de que o produto está cobrindo totalmente as plantas. Essa névoa, entretanto, pode ser formada por gotas muito pequenas $(<100 \mu \mathrm{m})$, que são volatilizadas ou arrastadas facilmente, não atingindo o alvo 
(Gassen, 2003). Gotas menores que $50 \mu \mathrm{m}$ permanecem no ar indefinidamente ou até a sua completa evaporação (Zhu et al., 1994; Ramos, 2001). A velocidade com que o tamanho da gota diminui é mais rápida sob circunstâncias tropicais, com temperaturas maiores e condições de baixa umidade (Matthews, 1992). Nestas circunstâncias, uma grande proporção da pulverização não pode ser coletada dentro da área que está sendo tratada, pois o movimento ascendente de gotas pequenas $(<100 \mu \mathrm{m})$ é contrabalançado pelas correntes que deslocam as gotas para outras partes. Quando as áreas envolvidas são relativamente pequenas, as correntes podem depositar gotas em uma área totalmente diferente, contaminando outras lavouras ou pastos (Matthews, 1992). Por outro lado, gotas grandes não conseguem penetrar na cultura, colidindo com a primeira camada de folhas e proporcionando escorrimento (Matuo et al., 2003). Nordbo (1992) esclarece que a aplicação sob maiores volumes de pulverização, associada às gotas maiores, frequentemente diminui a quantidade de ingrediente ativo retido na folha por causa do escorrimento da calda de sua superfície para outros pontos. Ressalta ainda que o espectro de gotas produzido por um determinado bico é uma complexa função na qual estão envolvidas as propriedades físicas do líquido, seu diâmetro e a pressão de operação.

Estudo realizado por Zhu et al. (1994) demonstra que gotas de $200 \mu \mathrm{m}$ de diâmetro apresentam deriva inferior quando comparado a gotas de $100 \mu \mathrm{m}$. Em vento com velocidade de $5,0 \mathrm{~m} \cdot \mathrm{s}^{-1}$ e $60 \%$ de umidade relativa, gotas de $100 \mu \mathrm{m}$ sofreram deriva de 6,48 metros, enquanto que os desvios de gotas de $200 \mu \mathrm{m}$ foram 0,$04 ; 0,36$ e 0,82 metros quando submetidas a velocidades de vento 0,$5 ; 5,0$ e $10 \mathrm{~m} . \mathrm{s}^{-1}$, respectivamente. A umidade relativa variando no intervalo de 20 a $100 \%$ teve influência muito limitada em se tratando de deriva e redução de gotas de $200 \mu \mathrm{m}$ de diâmetro (Zhu et al., 1994). 
Segundo Bode (1987) as gotas com diâmetros inferiores a $20 \mu \mathrm{m}$ podem evaporar em menos de $1 \mathrm{~s}$, o que corresponde a uma trajetória vertical de aproximadamente $2 \mathrm{~cm}$. Por outro lado, gotas com diâmetros superiores a $150 \mu \mathrm{m}$ apresentam resistência à evaporação muito maior do que as de tamanho menores. Segundo suas informações, a razão primordial para explicação desse fato é a maior relação existente entre o volume e a área das gotas maiores.

Gotas de água de $50 \mu \mathrm{m}$ ou menores são muito suscetíveis a deriva e evaporam antes de atingirem $0,5 \mathrm{~m}$ abaixo do ponto de descarga sob velocidades do vento de 0,5 a $10 \mathrm{~m} \cdot \mathrm{s}^{-1}$ e umidade relativa entre 20 e $80 \%$. A deriva destas gotas aumenta rapidamente com a ação de ventos crescentes, sendo que a $60 \%$ de umidade relativa quando em velocidades de ventos 0,5 ; 5,0 e $10 \mathrm{~m} . \mathrm{s}^{-1}$ se deslocaram a $3,86,22,1$ e 42,1 metros, respectivamente, antes de completamente evaporadas (Zhu et al., 1994).

A dose de produto contida em uma folha do algodoeiro, como consequência de um número de gotas por área de folha, pode ser mantida, na mesma folha, aumentando a densidade de deposição de gotas, ou seja, através da geração de gotas menores e em maior quantidade. Se a praga alvo apresentar boa movimentação, a menor densidade de deposição de gotas não interferirá na eficácia do seu controle (Matthews, 1992; Himel, 1969), o que entretanto poderá não ocorrer com pragas de pouca ou nenhuma mobilidade. De acordo com Chaim (1999), os valores de DMV não devem ser utilizados em conjunto com a densidade para se estimar o volume depositado.

Em uma aplicação, entende-se por cobertura a porcentagem da área alvo coberta pelo produto aplicado, e por deposição, a quantidade de produto fitossanitário coletado pelo alvo. Para que se tenha uma visão global dos resultados físicos provenientes do fracionamento dos produtos químicos aplicados, é fundamental o estudo dos níveis de cobertura e distribuição sobre os alvos, o que somente será possivel com uma precisa coleta de informações, 
as quais podem ser obtidas sobre coletores (Carvalho \& Furlani Junior, 1997). Carvalho \& Furlani Junior (1997) compararam coletores para determinação do DMV e do coeficiente de dispersão na amostragem de gotas em aplicações de produtos líquidos e os resultados demonstraram que o papel hidrossensivel e o papel colchekote não diferem estatisticamente do padrão (óxido de magnésio), portanto, em função da maior praticidade da utilização, os papéis podem ser considerados como as melhores alternativas para estas determinações. Qualquer que seja o coletor utilizado na captura de gotas, entretanto, deve-se levar em consideração na análise dos resultados que estas gotas, tendo sido coletadas sobre superfícies planas, perdem a característica de esfera passando a forma de uma calota esférica. Assim, para a correta determinação dos valores reais do diâmetro é necessário o conhecimento de um fator de espalhamento (Matthews, 1979; Sistler et al., 1982).

Para uma boa distribuição do produto na planta é preciso caracterizar corretamente fatores como DMV, uniformidade do tamanho das gotas, densidade de gotas e qualidade de cobertura da pulverização (Ozmeri \& Cilingir, 1992). A consideração do tamanho de gota em pulverizações, no entanto, é bastante complicada para uso por leigos e sua determinação é praticamente impossivel na propriedade agrícola. Mesmo em laboratório, a evolução dos equipamentos de análise fez com que resultados bastante discrepantes no DMV passassem a ser obtidos em função da precisão do equipamento utilizado, razão pela qual, a partir da década de 90 , o limite entre classes de pulverização passou a ser identificado não mais por um DMV fixo (Tabela 2) mas sim pelo DMV produzido por pontas padrão (Tabela 3), analisadas dentro do mesmo sistema de determinação (Ramos, 2001).

Pesquisadores enfatizam o espectro de gotas gerado como sendo primordial para análise técnica de resultados físicos e biológicos da calda pulverizada em culturas. Como visto, a gota tem uma relação estreita com o alvo a atingir, evaporação e deriva e a aferição do tamanho de gotas, na 
maioria das vezes, ocorre por intermédio da amostragem de quantidade significativa, devendo esta ser representativa e sobre superfícies adequadas (Yates et al., 1974, 1976; Matthews, 1979; Reichard, 1992). A rápida e correta análise dos resultados obtidos nestas amostras tem se tornado também muito importante, razão pela qual várias técnicas buscando dar agilidade ao processo de medição de gotas vêm sendo desenvolvidas. Entre tais técnicas, a análise de imagem, visando quantificar os depósitos da pulverização e distribuições de tamanho da gota sobre cartões ou amostradores, vem sendo estudada e alguns trabalhos já podem ser encontrados na literatura (Sistler et al., 1982; Franz, 1993; Raetano, 2001). Jiang \& Derksen (1995), por exemplo, desenvolveram um sistema de processamento morfológico de imagens de depósitos de gotas. As imagens foram capturadas por uma câmera CCD monocromática e o software utilizado permitiu medir manchas de gotas entre 5 e $1.000 \mu \mathrm{m}$. No Brasil, o programa de computador e-Sprinkle, desenvolvido pela EMBRAPA e comercializado pela Ablevision Sistemas Computacionais Ltda, teve sua precisão confirmada cientificamente por Ramos et al. (2004) para dimensionamento de gotas de pulverização coletadas em papéis hidrossensiveis, através da imagem dos mesmos digitalizadas com 600 pontos por polegada (ppp) ou "dot per inch" (dpi). 
Tabela 2. Classificação da pulverização segundo tamanho das gotas (FAO, 1996).

\begin{tabular}{cc}
\hline Classificação & Diâmetro Mediano Volumétrico $(\mu \mathrm{m})$ \\
\hline Aerosol fino & $<25$ \\
Aerosol grosso & $25-50$ \\
Pulverizado muito fino & $50-100$ \\
Pulverizado fino & $100-200$ \\
Pulverizado médio & $200-300$ \\
Pulverizado grosso & $300-400$ \\
Pulverizado muito grosso & $>400$ \\
\hline
\end{tabular}

Tabela 3. Pontas de referência para classificação da pulverização (FAO, 1998).

\begin{tabular}{lccc}
\hline Tipo de ponta & Vazão $\left(\mathrm{L} \mathrm{m}^{-1}\right)$ & Pressão $(\mathrm{kPa})$ & Categorias limites \\
\hline Leque $110^{\circ}$ & 0,48 & 450 & muito fina e fina \\
Leque $110^{\circ}$ & 1,20 & 300 & fina e media \\
Leque $110^{\circ}$ & 1,96 & 200 & média e grossa \\
Leque $80^{\circ}$ & 2,92 & 250 & $\begin{array}{c}\text { grossa e muito } \\
\text { grossa }\end{array}$ \\
\hline
\end{tabular}

2.4 Emprego de papéis hidrossensíveis no estudo de gotas de pulverização

Autores como Reichard et al. (1992) relatam as dificuldades da condução de ensaios à campo com pulverizadores, enfatizando que as condições meteorológicas não podem ser pré determinadas e/ou controladas, e que as variáveis que propiciam a deriva são muitas e certamente agem durante a condução do ensaio. Segundo eles, a simulação em laboratório minimiza problemas da condução de ensaios se levando em conta a ação isolada de cada fator, que não age de forma independente, sendo necessária a validação de modelos de simulação. Contudo, experimentos assim só podem ser 
realizados em condições controladas para fornecer dados seguros. Por outro lado, autores como Yates et al. $(1966,1974,1976)$, apesar de concordarem com a grande influência de fatores climáticos em pulverizações, cabendo destaque ao vento, asseguram e utilizam múltiplas passagens sobre a área de amostragem com o objetivo de dar confiabilidade à coleta de resíduos e resultados médios de depósitos de pulverização.

Uma técnica utilizada para estudo de tamanhos de gotas, muito empregada no caso da pulverização, é a análise feita a partir de papéis hidrossensiveis, que são papéis embebidos com o corante azul de bromofenol. O corante, que na sua forma não ionizada apresenta coloração amarela, quando em contato com a água, ioniza-se tornando-se azul (Turner \& Huntington, 1970). A praticidade do seu uso, bem como a confiabilidade dos resultados quando comparados a outras formas de tradicionais de amostragem, como o óxido de magnésio, foram comprovadas por diferentes autores (Carvalho, 1995; Carvalho \& Furlani Júnior, 1997; Fox et al., 2003). São habitualmente utilizados também na avaliação da densidade e distribuição de gotas, da largura da faixa de deposição e da penetração do líquido pulverizado na folhagem.

Em trabalho desenvolvido para avaliar e comparar a cobertura da pulverização com diferentes equipamentos e condições operacionais na cultura do café, o papel hidrossensivel foi utilizado para coletar gotas. Após as pulverizações, esses papéis foram encaminhados ao laboratório para análise da densidade e do diâmetro médio volumétrico (DMV) das gotas com o auxílio do software e-Sprinkle desenvolvido pela EMBRAPA e comercializado pela Ablevision Sistemas Computacionais Ltda. As maiores variações no DMV das gotas detectadas pelo software foram de 73,5 a $243,7 \mu \mathrm{m}$, independendo da posição de amostragem da planta (Raetano, 2001). Ramos et al. (2004) confirmaram a precisão do software e-Sprinkle, versão 2004, no dimensionamento de gotas de pulverização em imagens digitalizadas com 600 
pontos por polegada (ppp), ou "dot per inch" (dpi), de amostras coletadas sobre papéis hidrossensiveis, validando sua utilização para fins científicos.

Womac et al. (2001), analisando as interferências na uniformidade da aplicação proporcionadas por pontas de jato plano leque com indução de ar (DMV's de 474, 513, 579 e $663 \mu \mathrm{m}$ ) e pela velocidade do pulverizador $(6,4$; 12,$9 ; 19,3$ e $25,7 \mathrm{~km} \cdot \mathrm{h}^{-1}$ ), comparando com uma ponta de jato plano leque de pressão extendida (DMV de $187 \mu \mathrm{m}$ ), todas aplicando 93,5 L.ha-1 ${ }^{-1}$ observaram que velocidades até $25,7 \mathrm{~km} \cdot \mathrm{h}^{-1}$ não reduziram a quantidade ou incrementaram a variação nos depósitos de pulverização sobre papéis hidrossensiveis posicionados ao longo dos $27,4 \mathrm{~m}$ de barra do pulverizador. Notaram apenas uma tendência de redução na cobertura entre os bicos, na seção central da barra, entre o tratamento com $6,4 \mathrm{~km} \cdot \mathrm{h}^{-1}$ e DMV de $663 \mu \mathrm{m}$ e o tratamento controle com 19,3 km.h. ${ }^{-1}$ e DMV de $187 \mu \mathrm{m}$. Nestes ensaios, as pulverizações foram realizadas sobre terreno gramado com velocidades do vento sempre inferiores a $5 \mathrm{~km} \cdot \mathrm{h}^{-1}$. 


\section{MATERIAL E MÉTODOS}

\subsection{Características do campo experimental}

Com a proposta de avaliar a penetração de gotas de pulverização na cultura do algodoeiro em diferentes alturas de planta, foram instalados dois experimentos no ano agrícola de 2003/2004 em lavoura comercial da Fazenda Xingu, localizada no Município de Ituverava - SP, latitude de $2017^{\prime} 48^{\prime \prime} \mathrm{S}$ e longitude de $4756^{\prime} 50^{\prime \prime} \mathrm{O}$.

A cultivar Delta Opal, utilizada nos ensaios, é uma cultivar de porte médio, com ramos frutíferos curtos e desenvolvimento vegetativo normal semideterminado (Ornellas et al., 2001). Possui ramos oblíquos, maçãs pequenas, sendo cultivada em todas as regiões produtoras de algodão (MDM \& Delta and Pine Land Company, s.d.). A semeadura ocorreu no dia 17 de novembro de 2003 e a emergência das plântulas em 21 de novembro.

As pulverizações foram realizadas sobre plantas de algodão espaçadas entre linhas de 0,95 m, com média de 8 plantas por metro linear, em 2 diferentes estádios fenológicos. No primeiro (janeiro/2004) as plantas estavam com 11 internódios (desenvolvimento vegetativo e primeiros botões florais), 54 dias após emergência e altura média de $0,80 \mathrm{~m}$ (Experimento 1), enquanto que no segundo (fevereiro/2004) estavam com 19 internódios (desenvolvimento vegetativo e formação de maçãs), 90 dias após a emergência e altura média de 1,0 m (Experimento 2) (Figura 1). 


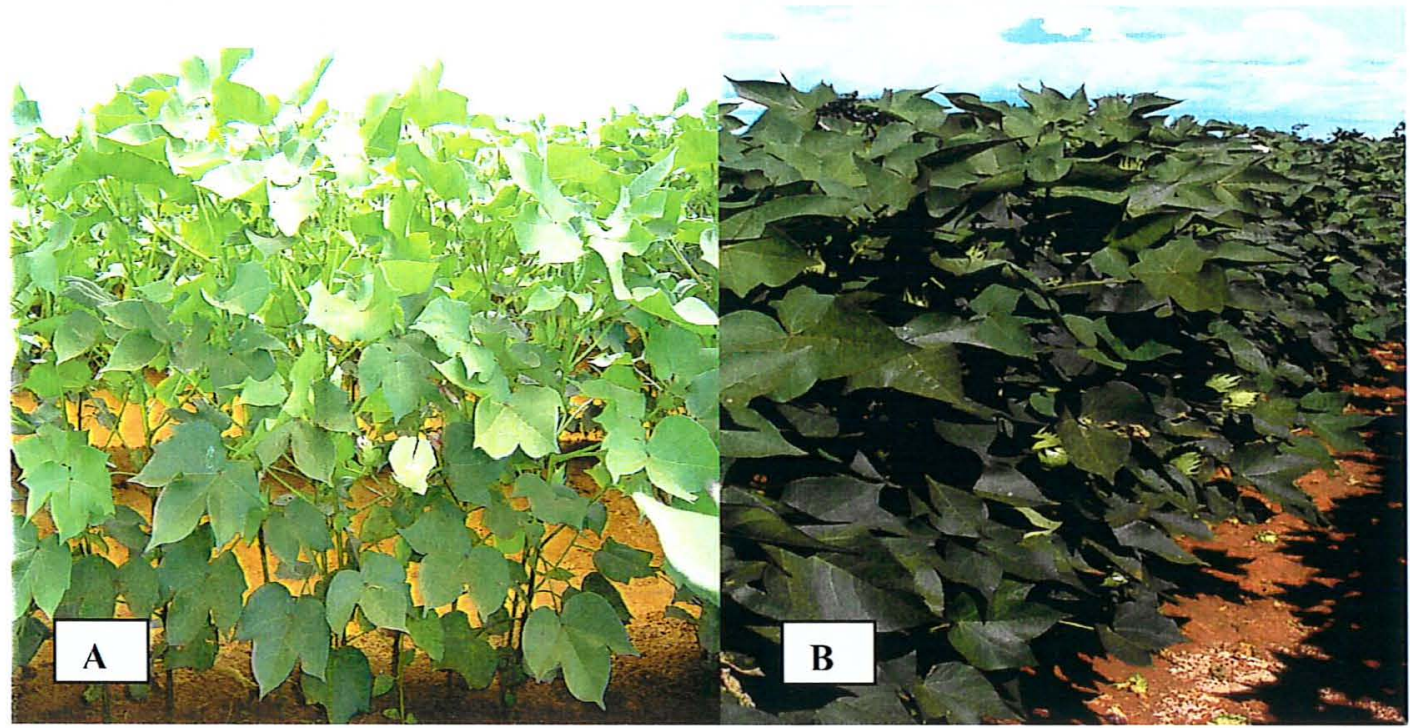

Figura 1 - Plantas alvo dos experimentos 1 (A) e 2 (B), na lavoura comercial de algodão da Fazenda Xingu em Ituverava, SP.

Todas as plantas selecionadas eram bem desenvolvidas, bem enfolhadas e com a ausência de clareiras, buscando-se proporcionar a máxima dificuldade à penetração da calda. Para todos os tratamentos foram utilizadas as mesmas plantas, minimizando a interferência proporcionada pela diferença de arquitetura da planta e pelo índice de área foliar. Assim, o conjunto de plantas alvo era sempre o mesmo para tratamentos e repetições, uniformizando a dificuldade de penetração de gotas para todos os tratamentos.

\subsection{Equipamento de pulverização}

\subsubsection{Pontas de pulverização}

As pontas de pulverização de jato plano leque utilizadas nos ensaios foram selecionadas de forma a apresentarem um mesmo padrão de distribuição da pulverização e, segundo informações do fabricante, DMV's de 
aproximadamente $200,250,300,350$ e $400 \mu \mathrm{m}$ dentro da faixa de pressão recomendada, que constituíram os tratamentos. A distribuição dos tratamentos de pulverização e suas respectivas pontas estão descritas na Tabela 4. As vazões das pontas de pulverização foram analisadas previamente $e$ individualmente, nas diferentes pressões a serem utilizadas em cada tratamento, para assegurar sua uniformidade.

As pontas selecionadas, com as vazões devidamente aferidas, foram mantidas na barra de pulverização sempre na mesma posição, utilizandose 24 bicos espaçados de $0,50 \mathrm{~m}$ entre si no Experimento 1 e de $0,33 \mathrm{~m}$ no Experimento 2, que eram os espaçamentos entre pontas adotados nos pulverizadores utilizados.

Tabela 4. Arranjo de pontas para avaliação da eficácia da penetração de gotas de pulverização na copa do algodoeiro em diferentes fases vegetativas (Ituverava-SP, 2004).

\begin{tabular}{cccc}
\hline Tratamento & Modelos de Pontas & Pressão $(\mathrm{KPa})$ & DMV $(\mu \mathrm{m})^{(1)}$ \\
\hline T1 & XR 11002 & 450 & 200 \\
T2 & XR 110 02 & 200 & 243 \\
T3 & XR 110 02 & 100 & 297 \\
T4 & XR 110 06 & 200 & 358 \\
T5 & XR 110 06 & 100 & 396 \\
\hline
\end{tabular}

(1) Dados fornecidos pela Spraying Systems Co.

\subsubsection{Certificação dos valores de DMV's fornecidos pelo fabricante}

A certificação dos valores dos DMV's fornecidos pelo fabricante foi realizada de duas diferentes maneiras: através da análise da pulverização das pontas utilizadas em equipamento de leitura a laser e através da coleta de gotas 
sobre papéis hidrossensiveis em laboratório e posterior digitalização e análise no programa de computador e-Sprinkle.

A avaliação do tamanho das gotas no laser foi realizada no Laboratório do Departamento de Fitossanidade da Faculdade de Ciências Agrárias e Veterinárias da Universidade Estadual Paulista (UNESP), em Jaboticabal (SP), utilizando-se um equipamento da marca Malvern, modelo Mastersizer. Para análise, as pontas foram posicionadas a aproximadamente 50 $\mathrm{cm}$ acima do laser e a $50 \mathrm{~cm}$ do ponto de emissão (posição mais adequada à leitura de gotas abaixo de $700 \mu \mathrm{m}$ ) e colocadas a trabalhar nas pressões determinadas. Durante a avaliação, o bico era movimentado automaticamente de modo que o leque interceptasse transversalmente o laser, permitindo a amostragem de toda a área de pulverização. Foram selecionadas três pontas de cada modelo, que analisadas individualmente em cada uma das pressões, constituíram uma repetição.

A coleta de gotas, o processamento das amostras e a determinação do DMV no programa de computador e-Sprinkle foram realizados no Laboratório de Tecnologia de Aplicação de Produtos Fitossanitários do Centro de Engenharia e Automação do Instituto Agronômico (CEA/IAC), em Jundiaí (SP). Visando reduzir a densidade de gotas a atingir o alvo, facilitando assim a individualização das mesmas nas análises, utilizou-se um dispositivo (Figura 2) composto por 2 placas de acrílico: uma fixa, inferior, com uma abertura circular de $13,1 \mathrm{~cm}$ de raio e outra móvel, superior, com abertura retangular de 5,0 x 25,5 cm, impulsionada por um sistema pneumático. Para coleta das gotas, 5 papéis hidrossensiveis foram posicionados $44 \mathrm{~cm}$ abaixo das placas e as pontas de pulverização $6 \mathrm{~cm}$ acima das mesmas. Após o posicionamento, o circuito hidráulico foi ligado, acionando-se, com a uniformização da pulverização, o sistema pneumático para que a placa deslizasse sob o jato. Isso fez com que o tempo de exposição do papel fosse restrito ao momento de sobreposição das aberturas das placas, limitando o 
número de gotas a atingir a superfície de amostragem. O sistema hidráulico estacionário era acionado por um motor elétrico de $1 \mathrm{HP}$ e a pressão controlada por meio de um manômetro padrão de $700 \mathrm{Kpa}$. Foram selecionadas três pontas de cada tratamento entre aquelas selecionadas para uso nos ensaios de campo (Tabela 4) que, analisadas individualmente, constituíram uma repetição. Os 15 papéis hidrossensíveis assim obtidos para cada tratamento foram digitalizados por meio de 'scanner' marca HP, modelo PSC 500, com 1200 ppp (ou dpi) e 24 milhões de cores, salvos no formato BMP e analisados no programa de computador e-Sprinkle como uma única amostra. Durante as amostragens das gotas, realizadas em 29/03/05 entre $9: 40$ às 12:37 horas, a umidade relativa média foi de $50,64 \%$ e a temperatura média de $30{ }^{\circ} \mathrm{C}$.

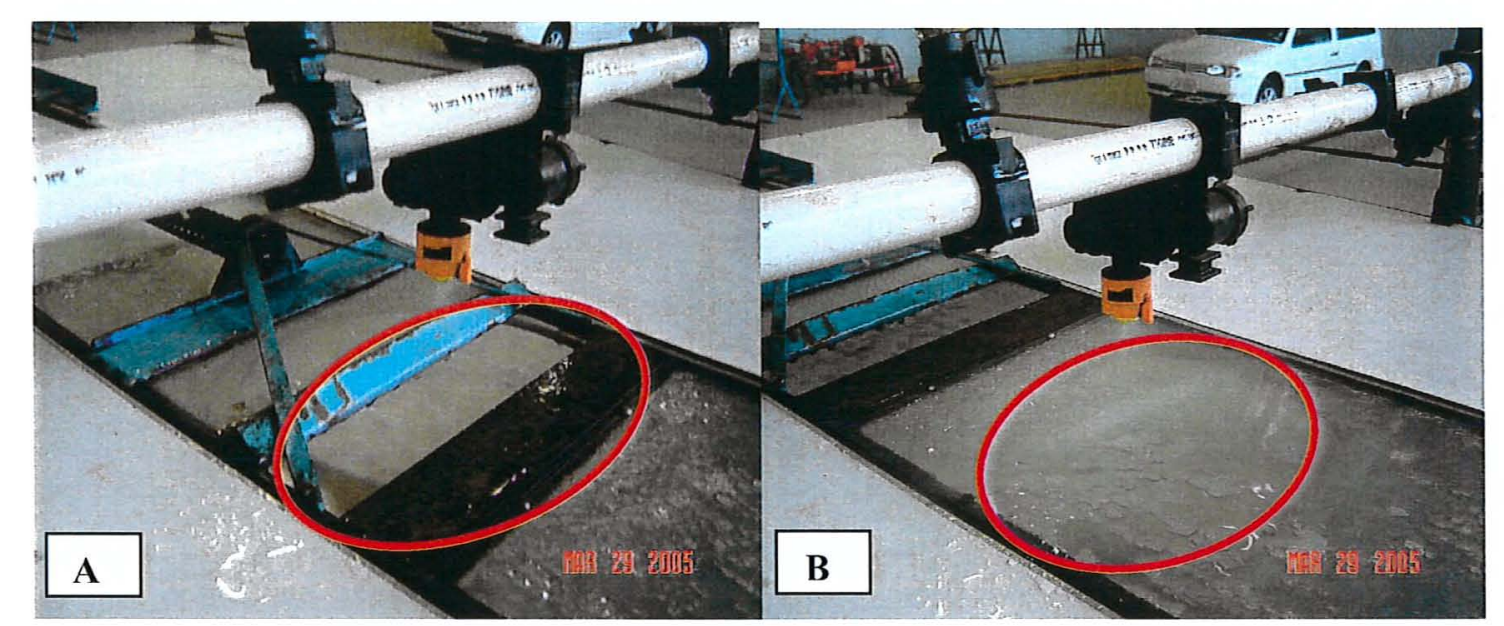

Figura 2 - Sistema para limitação do número de gotas da pulverização coletadas sobre papel hidrossensível, evidenciando o restritor da pulverização aberto (A) e fechado (B).

Os resultados obtidos para os tamanhos de gotas utilizados nos ensaios podem ser visualizados no Quadro 2. Observa-se uma grande diferença nos resultados obtidos entre as diferentes técnicas de avaliação, muito possivelmente em função de diferenças na precisão entre os equipamentos e 
métodos utilizados, conforme o já citado por Ramos (2001). Para os dois equipamentos laser (fabricante e ensaio), a explicação mais lógica para a diferença observada seria uma diferença significativa na precisão de detecção de gotas pequenas. Quanto maior esta precisão, maior a representatividade destas no processo e, conseqüentemente, menor o valor do DMV obtido. Quanto às diferenças entre os DMV's fornecidos pelo fabricante e os obtidos no e-Sprinkle, observa-se que as diferenças são crescentes com a vazão e o tamanho de gotas. Isso ocorreu porque, mesmo com a alta velocidade de deslocamento das placas de acrílico, notou-se uma sobreposição de gotas sobre os amostradores, que foi crescente com o volume. Como o programa foi desenvolvido para análise de gotas sobre um alvo (coletor), e não das gotas em queda, ele considera que duas gotas com sobreposição maior do que $50 \%$ sobre o alvo biológico comporta-se-ão como uma única gota, considerando-a portanto como única. Assim, tais sobreposições elevam o tamanho da gota e podem explicar o DMV elevado.

\begin{tabular}{|c|c|c|c|c|}
\hline \multirow{2}{*}{ Tratamentos } & Ponta & \multicolumn{3}{|c|}{ DMV $(\mu \mathrm{m})$} \\
\cline { 3 - 5 } & & Fabricante & e-Sprinkle & Laser \\
\hline 1 & XR 110 02 & 200 & 290 & 130 \\
\hline 2 & XR 110 02 & 243 & 350 & 167 \\
\hline 3 & XR 110 02 & 297 & 451 & 264 \\
\hline 4 & XR 110 06 & 358 & 464 & 290 \\
\hline 5 & XR 110 06 & 396 & 605 & 397 \\
\hline
\end{tabular}

Quadro 2 - Análise dos diâmetros de gotas fornecidos pelo fabricante comparados aos diâmetros obtidos no software E-sprinkle e no analisador laser. 


\subsubsection{Experimento 1}

O presente ensaio, que corresponde ao primeiro estádio fenológico, foi montado em 13 de janeiro de 2004, quando as plantas de algodão estavam com altura média de $0,80 \mathrm{~m}$.

\subsubsection{Características do pulverizador}

As pulverizações foram realizadas com um pulverizador de barras com jato lançado da marca Jacto, modelo Coral/Condor B-12 equipado com bomba hidráulica de pistões com capacidade de $75 \mathrm{~L} . \mathrm{min}^{-1}$ quando trabalhando a $540 \mathrm{rpm}$ na tomada de potência (TDP), tanque em plástico com capacidade de $600 \mathrm{~L}$ e barras com $12 \mathrm{~m}$ contendo 25 bicos espaçados de $0,50 \mathrm{~m}$.

\subsubsection{Velocidade de trabalho}

O pulverizador foi tracionado por um trator da marca Ford, modelo 6630 , trabalhando nas marchas $2^{a}$ e $3^{a}$ simples, com rotação dimensionada para proporcionar $540 \mathrm{rpm}$ na tomada de potência e deslocando-se a velocidades reais de $11,6 \mathrm{~km} \cdot \mathrm{h}^{-1}$ para os tratamentos 1,2 e 3 e $18,5 \mathrm{~km} \cdot \mathrm{h}^{-1}$ para os tratamentos 4 e 5 . Uma vez que a velocidade de deslocamento dentro das faixas adotadas não interfere sobre a cobertura no papel hidrossensivel, havendo apenas uma tendência de redução na região entre bicos da seção imediatamente atrás do pulverizador (Womac et al., 2001), as velocidades foram definidas para que, nas pressões pré-determinadas, houvesse quantidade suficiente de gotas sobre os amostradores com o mínimo possível de sobreposição entre elas (Tabela 5). 
Tabela 5. Características da pulverização realizada na cultura do algodoeiro, com $0,80 \mathrm{~m}$ de altura, para análise do espectro de gotas atingindo diferentes posições da planta (Ituverava-SP, 2004).

\begin{tabular}{|c|c|c|c|c|c|c|}
\hline Tratamento & Ponta & $\begin{array}{c}\text { Pressão } \\
\text { (kPA) }\end{array}$ & $\mathrm{DMV}^{(1)}$ & $\begin{array}{c}\text { Velocidade } \\
\left(\mathrm{km} \cdot \mathrm{h}^{-1}\right)\end{array}$ & $\begin{array}{c}\text { Vazão } \\
\left(L \cdot \min ^{-1}\right)^{(1)}\end{array}$ & $\begin{array}{l}\text { Volume } \\
\left(\text { L.ha }{ }^{-1}\right)\end{array}$ \\
\hline T1 & XR 11002 & 450 & 200 & 11,6 & 1,07 & 110,69 \\
\hline $\mathrm{T} 2$ & XR 11002 & 200 & 243 & 11,6 & 0,64 & 66,21 \\
\hline T3 & XR 11002 & 100 & 297 & 11,6 & 0,46 & 47,59 \\
\hline T4 & XR 11006 & 200 & 358 & 18,5 & 1,93 & 125,19 \\
\hline T5 & XR 11006 & 100 & 396 & 18,5 & 1,37 & 88,86 \\
\hline
\end{tabular}

(1) Dados fornecidos pela Spraying Systems Co.

\section{2.4 Experimento 2}

O presente ensaio foi instalado a campo em plantas de algodão com altura média de $1,0 \mathrm{~m}$, em 18 de fevereiro de 2004 .

\subsubsection{Características do pulverizador}

Foi utilizado um pulverizador autopropelido de barras com jato lançado, da marca Jacto, modelo Uniport, motor de 95,6 Kw, equipado com bomba hidráulica de pistões com capacidade de $150 \mathrm{~L} \cdot \mathrm{min}^{-1}$ quando trabalhando a $540 \mathrm{rpm}$ na tomada de potência (TDP), tanque em fibra de vidro com capacidade de $2000 \mathrm{~L}$ e barras com $21 \mathrm{~m}$ contendo 63 bicos espaçados de $0,33 \mathrm{~m}$. 


\subsubsection{Velocidade de trabalho}

O pulverizador trabalhando em $3^{\mathrm{a}}$ marcha, com rotações de $1400 \mathrm{e}$ $1800 \mathrm{rpm}$, deslocou-se a velocidades de $14,9 \mathrm{~km} \cdot \mathrm{h}^{-1}$ para os tratamentos 2 e $3 \mathrm{e}$ $15,6 \mathrm{~km} \cdot \mathrm{h}^{-1}$ para o tratamento 1. Quando trabalhando em $4^{\mathrm{a}}$ marcha, com rotações de 1400 e $1500 \mathrm{rpm}$, o autopropelido deslocou-se a velocidades de $18,0 \mathrm{~km} \cdot \mathrm{h}^{-1}$ para o tratamento 5 e $18,6 \mathrm{~km} \cdot \mathrm{h}^{-1}$ para o tratamento 4 . As variações na velocidade (Tabela 6 ) foram adaptadas pelos mesmos motivos já discutidos em 3.2.3.2 e, de acordo com Womac et al. (2001), estão dentro da faixa com deposição uniforme.

Tabela 6. Caracteristicas da pulverização realizada na cultura do algodoeiro, com 1,00 m de altura, para análise do espectro de gotas atingindo diferentes posições da planta. (Ituverava-SP, 2004)

\begin{tabular}{|c|c|c|c|c|c|c|}
\hline Tratamento & Ponta & $\begin{array}{c}\text { Pressão } \\
(\mathrm{kPa})\end{array}$ & $\mathrm{DMV}^{(1)}$ & $\begin{array}{c}\text { Velocidade } \\
\left(\mathrm{km} \cdot \mathrm{h}^{-1}\right)\end{array}$ & $\begin{array}{c}\text { Vazão } \\
\left(\text { L. } \min ^{-1}\right)^{(1)}\end{array}$ & $\begin{array}{l}\text { Volume } \\
\left(\text { L.ha }^{-1}\right)\end{array}$ \\
\hline T1 & XR 11002 & 450 & 200 & 15,6 & 1,07 & 82,31 \\
\hline T2 & XR 11002 & 200 & 243 & 14,9 & 0,64 & 51,54 \\
\hline T3 & XR 11002 & 100 & 297 & 14,9 & 0,46 & 37,05 \\
\hline T4 & XR 11006 & 200 & 358 & 18,6 & 1,93 & 124,52 \\
\hline T5 & XR 11006 & 100 & 396 & 18,0 & 1,37 & 91,33 \\
\hline
\end{tabular}

(1) Dados fornecidos pela Spraying Systems Co.

3.3 Coleta e preparação das amostras para determinação do tamanho das gotas 


\subsubsection{Desenvolvimento de suportes para fixação dos amostradores}

Para as coletas de gotas foram desenvolvidos suportes com a finalidade de fixar os amostradores no interior das plantas, compostos por uma haste vertical fixa de aproximadamente $1,0 \mathrm{~m}$ ao longo da qual podiam-se posicionar horizontalmente 3 lâminas de alumínio, com regulagem de altura e bordas devidamente dobradas, dentro das quais eram colocados os amostradores (Figura 3). Para as amostragens, 6 plantas foram marcadas na região ao longo da barra do pulverizador, distribuídas da seguinte forma: 3 de cada lado do trator, sendo uma próxima à ponta da barra, outra no centro e outra próxima ao pneu. Em cada planta posicionou-se, próximo ao centro da mesma, um amostrador com as 3 lâminas de alumínio posicionadas nos terços superior, médio e inferior da planta (Figura 4). Em cada lâmina devidamente ajustada fixou-se então 2 amostradores, um na parte superior e outro na inferior, simulando as folhas sem movimento. Cada conjunto de 6 plantas foi considerado 1 repetição, tendo-se realizado 4 repetições espaçadas de pelo menos $10 \mathrm{~m}$. Um croqui e imagem da área experimental podem ser visualizados nas Figuras 5 e 6. 

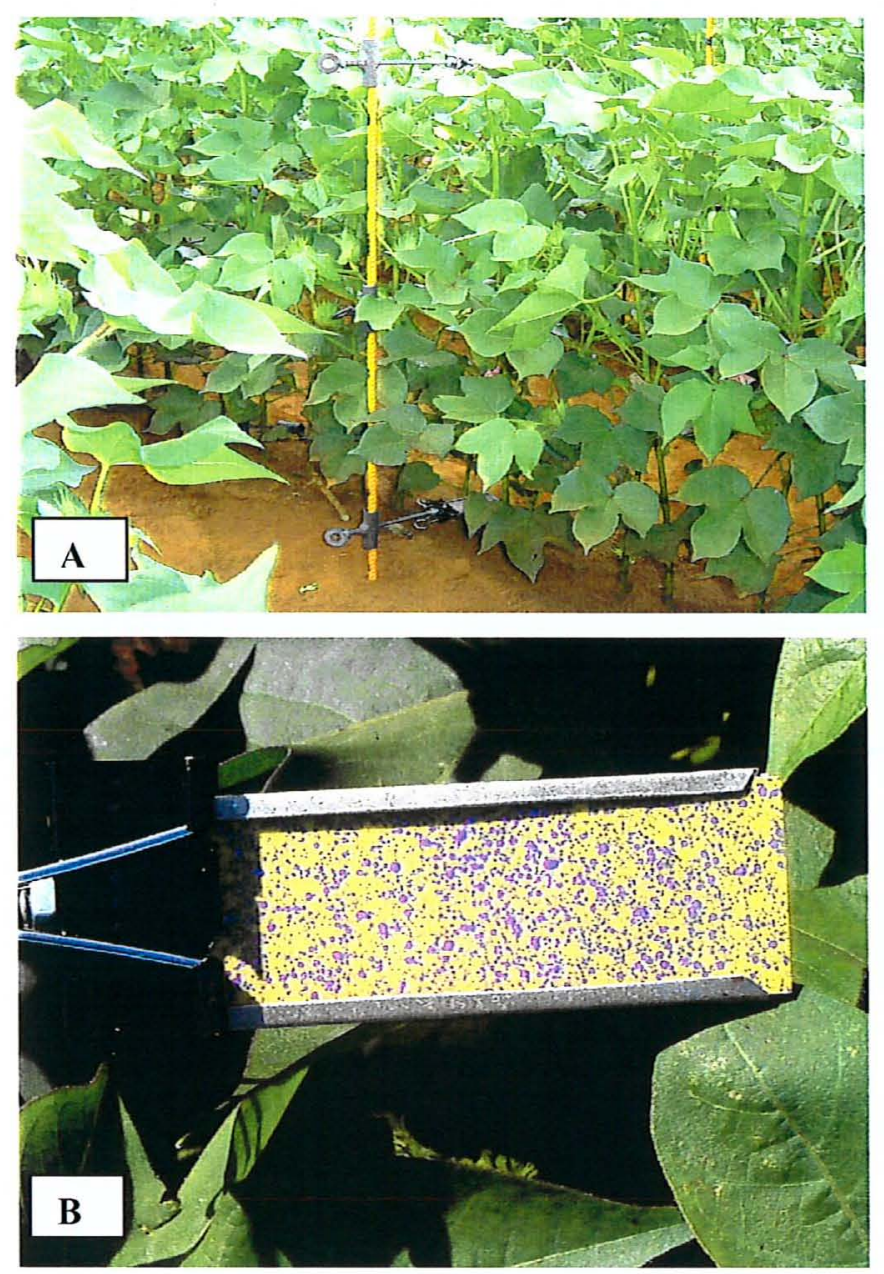

Figura 3 - Posicionamento dos suportes (A) e lâminas de alumínio (B), desenvolvidos para melhor acondicionar os papéis hidrossensíveis durante as amostragens de gotas no interior da cultura do algodoeiro. 


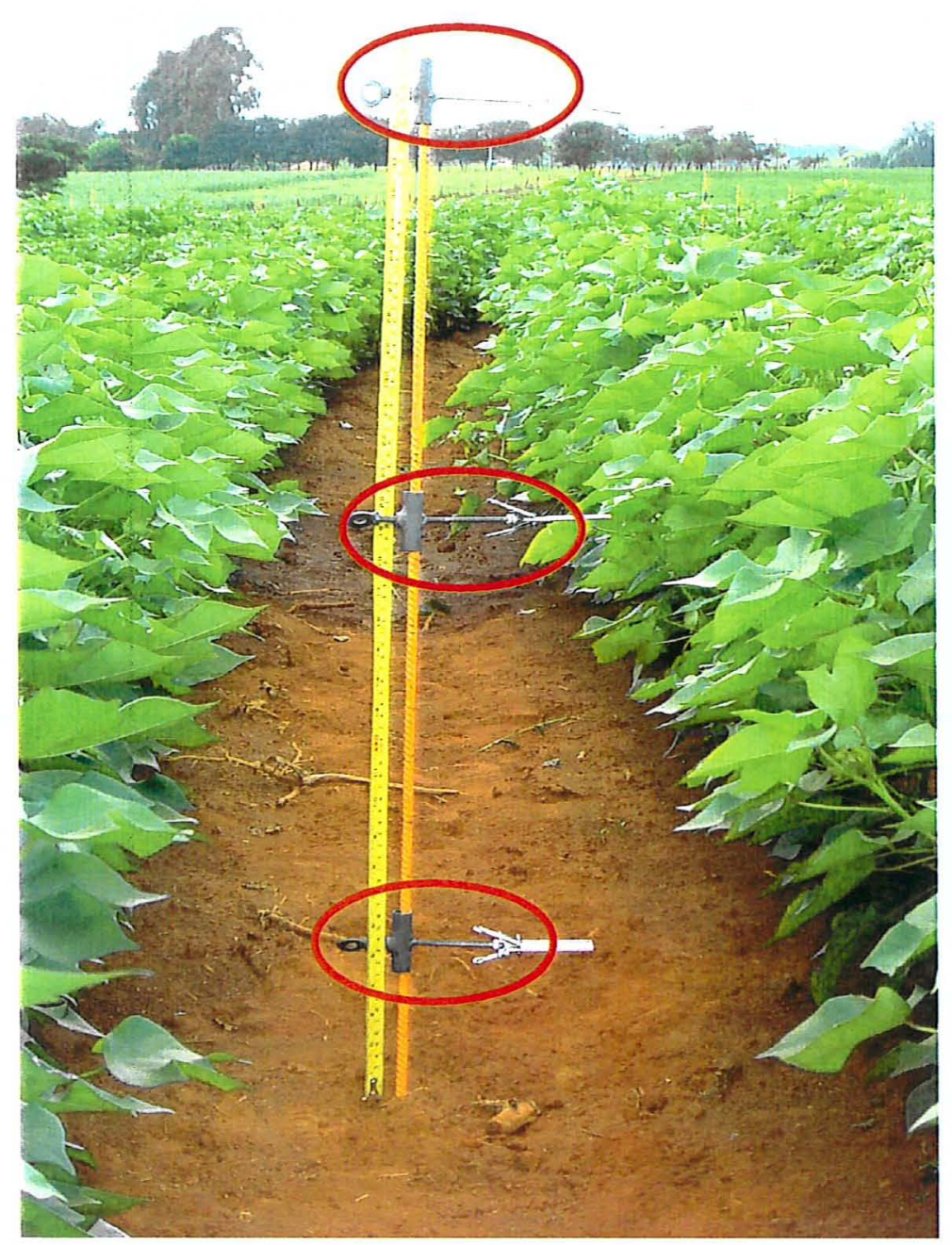

Figura 4 - Suporte e amostradores desenvolvidos para acondicionar os papéis hidrossensíveis durante as amostragens de gotas no interior da cultura do algodoeiro, evidenciando a regulagem de altura e movimentação lateral. 

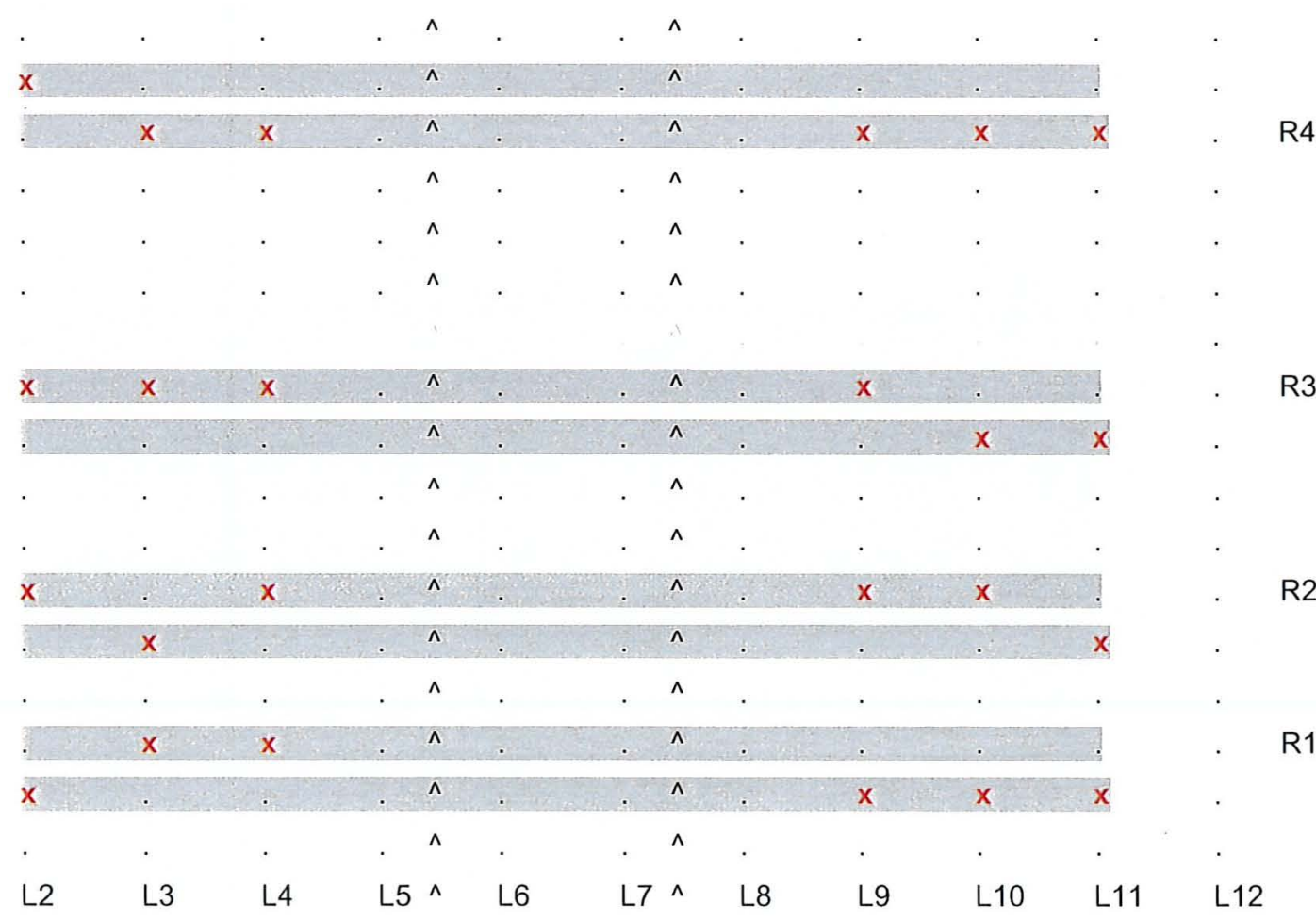

$\begin{array}{llllllllllllll}\text { L1 } & \text { L2 } & \mathrm{L} 3 & \mathrm{~L} 4 & \mathrm{~L} & \wedge & \mathrm{L} 6 & \mathrm{~L} 7 & \wedge & \mathrm{L} 8 & \mathrm{~L} 9 & \mathrm{~L} 10 & \mathrm{~L} 11 & \mathrm{~L} 12\end{array}$

|

Figura 5 - Croqui da área experimental evidenciando as linhas de semeadura (L1... L12), o caminhamento do rodado do equipamento de pulverização $\left({ }^{\wedge}\right)$ e as repetições (R1... R4), compostas por 6 plantas selecionadas (Ituverava-SP, 2004). 


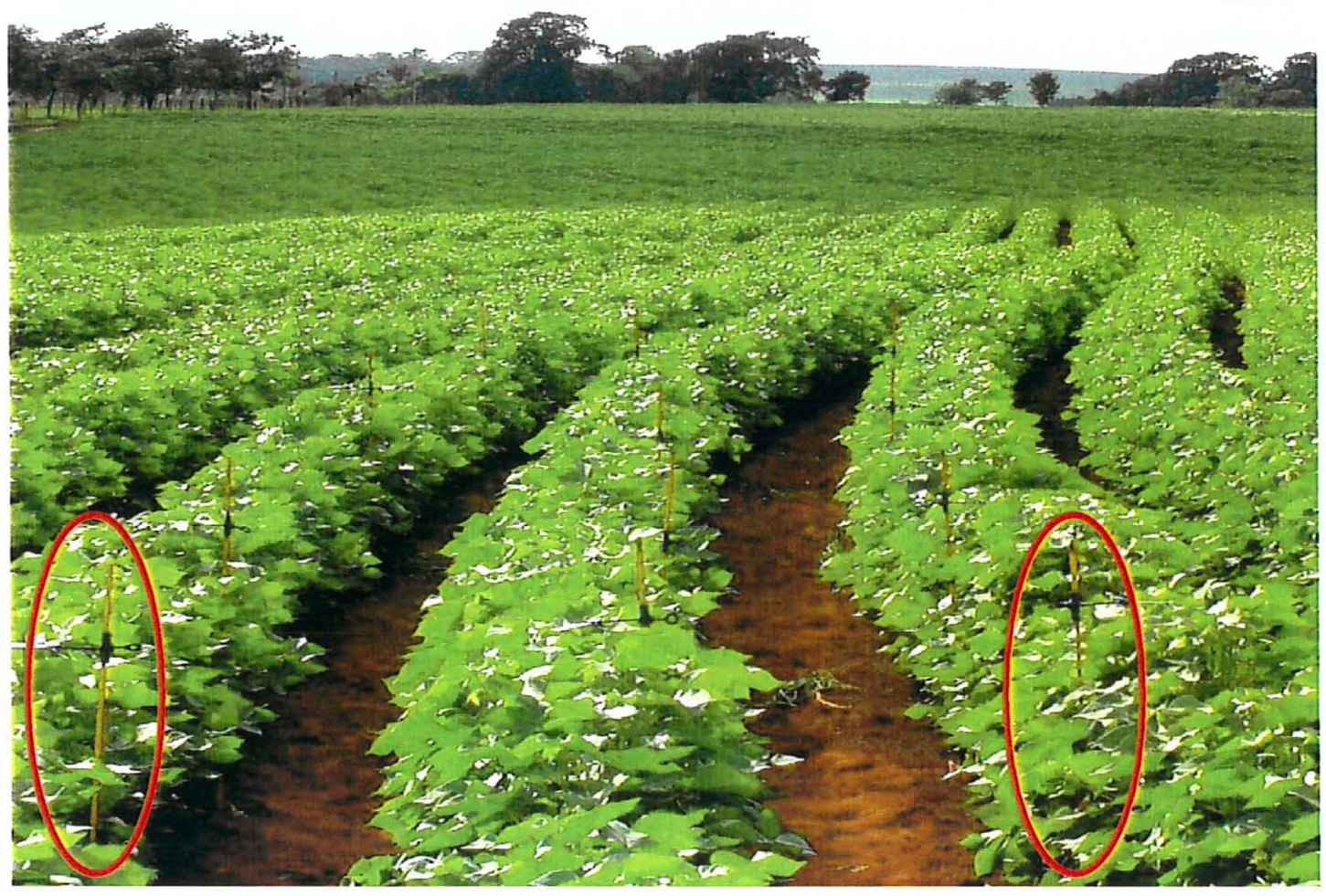

Figura 6 - Área experimental, com os suportes de amostragem devidamente dispostos para amostragem, nas plantas alvo selecionadas (ItuveravaSP, 2004).

\subsection{Amostradores}

Como amostrador para a coleta e determinação do tamanho de gotas dos diferentes tratamentos de pulverização, utilizou-se 0 papel hidrossensível segundo método já utilizado por Carvalho \& Furlani Junior (1997), Chain (2002) e Raetano (2001).

\subsection{Pulverizações}

As pulverizações, utilizando-se apenas água, foram realizadas em 13/01/2004, 54 dias após emergência e 18/02/2004, 90 dias após emergência, a 
0,50 m acima do topo das plantas, empregando-se as condições operacionais sumarizadas nas Tabelas 5 e 6 , respectivamente para os Experimentos 1 e 2 .

\subsection{Coleta e processamento das amostras}

\subsubsection{Coleta dos papéis hidrossensíveis}

Após as pulverizações, os papéis hidrossensiveis de cada planta foram devidamente coletados, afixados e identificados em folhas de papel A4, tomando-se o cuidaddo de manipulá-los pelas laterais, afim de não danificar as amostras. Os papéis foram embalados em sacos plásticos, devidamente identificados por tratamento e encaminhados para o laboratório para os procedimentos de avaliação.

\subsubsection{Aquisição das imagens dos papéis hidrossensiveis}

Para possibilitar a avaliação do tamanho de gotas, as imagens dos papéis hidrossensiveis coletados a campo foram digitalizadas por meio de 'scanner' marca HP, modelo PSC 500, com 600 ppp e 24 milhões de cores, e salvas no formato BMP (Figura 7), que é o formato recomendado pela Ablevision/Embrapa e certificado por Ramos et al. (2004) como adequado para análise no programa de computador e-Sprinkle, versão 2004.

\subsubsection{Resolução em pixels adotada para análise das gotas}

Cabe ressaltar que, como qualquer sistema eletrônico de análise, a determinação do tamanho de gotas efetuado pelo programa de computador eSprinkle é realizado por meio da análise de 'pixels', cujo tamanho unitário varia com a resolução da imagem. Como o tamanho da imagem em 'bytes' também é 
diretamente proporcional à sua resolução, interferindo no tempo e na capacidade de processamento da amostra, torna-se importante aliar a resolução aos resultados pretendidos. Neste trabalho, a resolução de 600 dpi foi adotada por permitir o dimensionamento de gotas com diâmetro mínimo de $95 \mu \mathrm{m}$, considerado adequado uma vez que gotas com diâmetros inferiores a $100 \mu \mathrm{m}$ são mais sujeitas à evaporação e deriva, devendo ser evitadas no campo (Reichard et al., 1992; Zhu et al., 1994; Gassen, 2003), e por ser esta a resolução recomendada por Ramos et al. (2004) para análise de gotas neste programa.

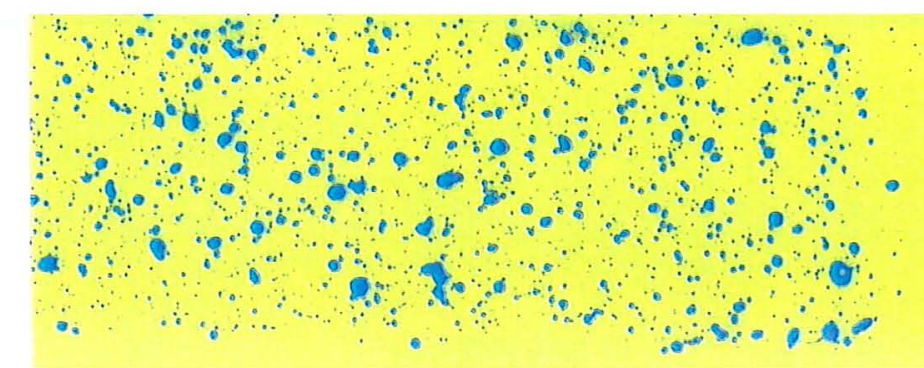

Figura 7 - Exemplo de papel hidrossensível digitalizado e utilizado para avaliação de tamanho de gota.

\subsubsection{Análise dos dados}

O dimensionamento das gotas foi realizado por meio do programa computacional e-Sprinkle, versão 2004, desenvolvido pela Embrapa/Ablevision e validado cientificamente por Ramos et al. (2004) para esta finalidade.

Para análise e comparação dos tamanhos de gotas em cada um dos pontos amostrados, utilizou-se dos resultados obtidos na análise conjunta dos 6 amostradores que constituíram uma repetição. Assim os papéis hidrossensíveis que representavam a parte superior da folha no terço médio da 
planta, por exemplo, foram analisados no programa como sendo 1 amostra contendo todas as gotas coletadas.

Uma vez realizadas as determinações dos tamanhos de gotas, optou-se por utilizar os dados relativos ao número de gotas por classe de tamanho, e não o diâmetro mediano volumétrico, uma vez que a eficácia de várias gotas pequenas em atingir o alvo poderia ser mascarada por apenas uma gota média ou grande caso este último fosse utilizado. Por fim, como os resultados evidenciassem que as gotas se distribuiam principalmente em 17 classes de diâmetro para todas as amostras, tais classes foram incorporadas à análise estatística, em conjunto com os tamanhos de gotas produzidas pelas pontas e as posições de amostragem.

Os dados foram analisados para cada época segundo um delineamento experimental inteiramente casualizado, dentro de um esquema fatorial $5 \times 3 \times 17$, correspondendo a 5 diâmetros medianos volumétricos definidos pelo fabricante da ponta de pulverização (Tabela 4), 3 posições na planta (terço superior, terço mediano e terço inferior) e 17 diâmetros de gotas encontrados sobre os amostradores.

\subsubsection{Condições Meteorológicas}

As condições meteorológicas, que se mantiveram relativamente estáveis em ambos os ensaios, foram registradas através de um anemômetro mecânico e um termo-higrômetro digital. As condições do Experimento 1 foram constituídas por temperatura e umidade relativa médias de $35,2^{\circ} \mathrm{C}$ e $63,3 \%$ respectivamente, vento com rajadas de até $2,25 \mathrm{~m} . \mathrm{s}^{-1}$, no periodo entre 11:00 horas e 14:05 horas. Para o Experimento 2, a temperatura e umidade relativas médias foram de $33,2^{\circ} \mathrm{C}$ e $63 \%$, a velocidade vento de até $3 \mathrm{~m} \cdot \mathrm{s}^{-1}$ e o período entre 14:42 horas e 17:50 horas. 


\subsubsection{Determinação do Índice de Área Foliar (IAF)}

Com a finalidade de melhor caracterização da cultura no momento das pulverizações, imediatamente após o término de cada experimento as plantas consideradas para avaliação da penetração de gotas foram arrancadas cuidadosamente, enumeradas com fita plástica (Figura 8), embaladas em saco plástico, tomando-se o máximo cuidado de não danificar ou perder as folhas, procurando preservar as folhas em suas respectivas plantas. Em seguida as amostras foram acondicionadas sob refrigeração à temperatura média de $18^{\circ} \mathrm{C}$ por até 3 dias para permitir as medições.

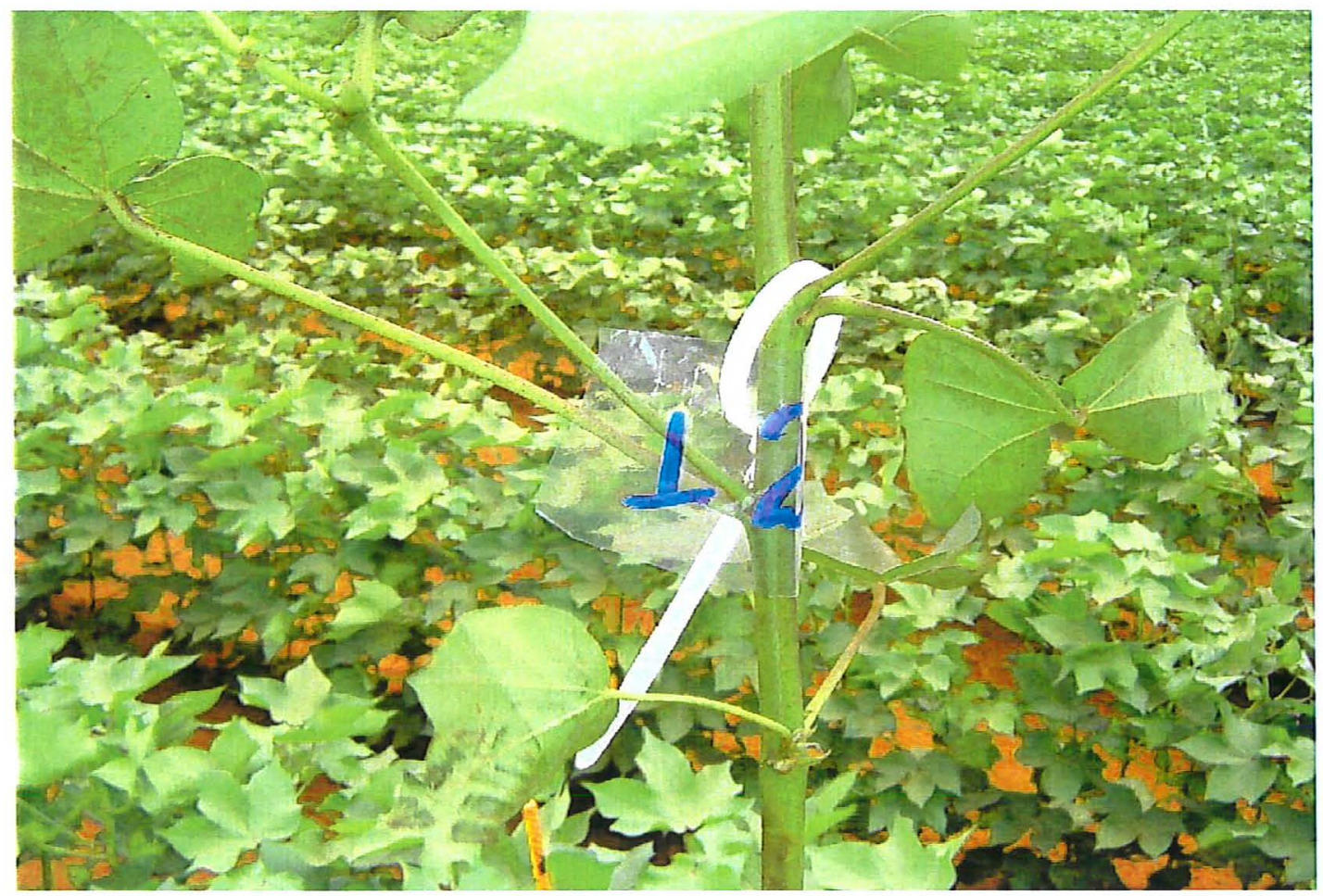

Figura 8 - Planta identificada pronta para ser embalada e encaminhada para medição de área foliar (Ituverava-SP, 2004).

Para a determinação da área foliar, as folhas de cada planta foram destacadas (Figura 9) e digitalizadas através de um scanner trabalhando com 
resolução ótica de 150 ppp. A determinação da área foliar foi então realizada, por meio das imagens obtidas, com auxilio do software $I D R I S I^{\circledR}$, segundo método adaptado de Lallana (1999) por pesquisadores do Centro de Engenharia e Automação do Instituto Agronômico, em Jundiaí (SP), cujos passos são descritos no Anexo A. Antes da sua utilização nos ensaios, a precisão do método foi avaliada através da comparação dos resultados obtidos em análises de figuras com áreas conhecidas (quadrados, círculos, etc).

Uma vez determinadas as áreas das folhas, O IAF foi calculado considerando-se a área foliar de uma planta como a somatória das áreas das folhas que a compunham e a área de solo ocupada pela planta como a esperada em função do espaçamento de plantio. 

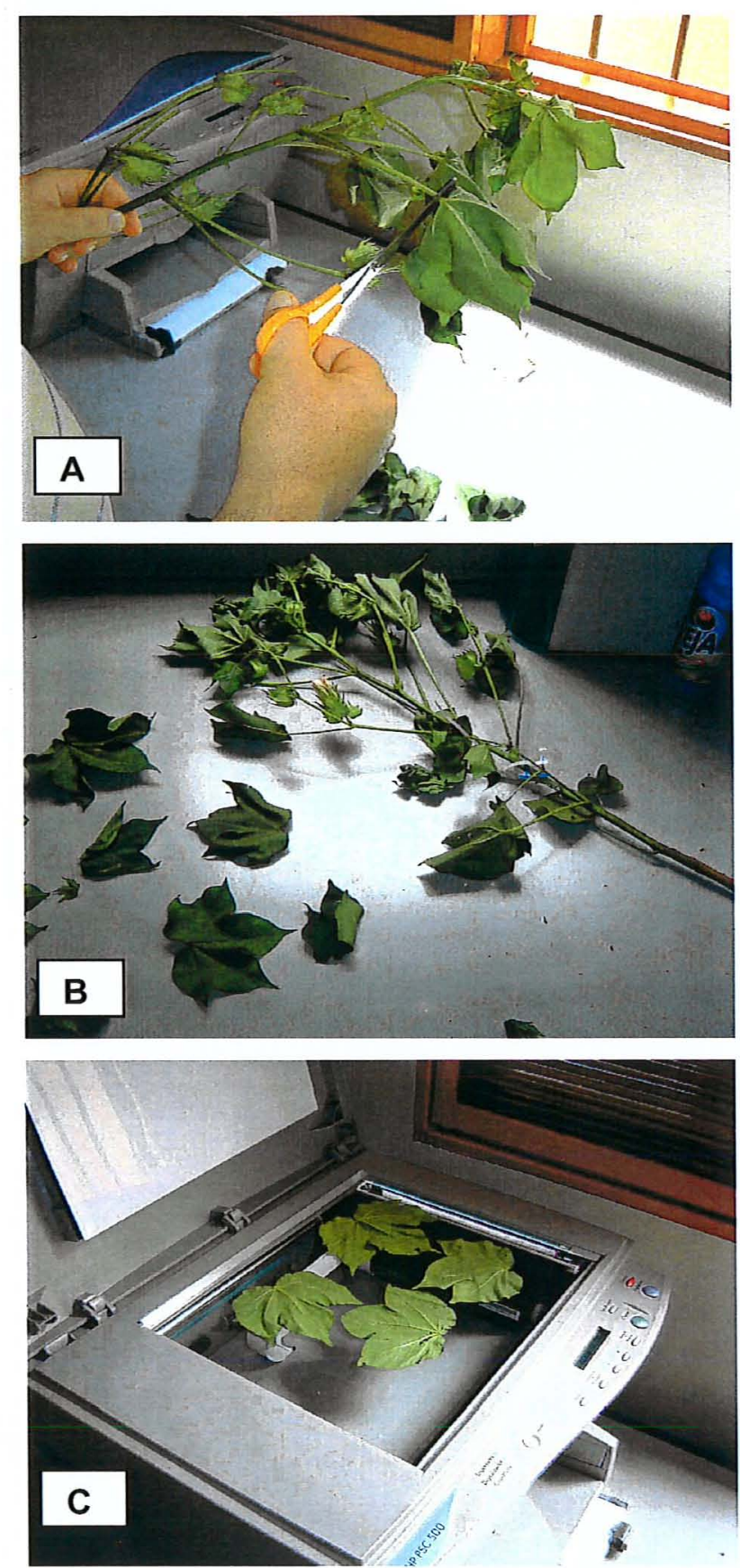

Figura 9 - Sistema utilizado na digitalização das folhas para cálculo do índice de área foliar evidenciando a separação dos ramos das folhas em plantas alvo (A), o cuidado em não danificar as folhas (B) a digitalização das mesmas (C). 


\section{RESULTADOS E DISCUSSÃO}

\section{1 Área foliar das plantas}

As áreas foliares das plantas de algodoeiro utilizadas nos Experimentos 1 e 2 são apresentadas nas Tabelas 7 e 8 . Analisando-se tais dados, verifica-se um coeficiente de variação de $13 \%$ entre as médias das repetições para Experimento 1 e de $14 \%$ para o Experimento 2, apesar de um aumento médio de $10.504,52 \mathrm{~cm}^{2}$, ou $605 \%$, na área foliar, evidenciando a homogeneidade das plantas dentro de uma mesma época e a acentuada diferença entre as duas condições de aplicação, como o proposto para este trabalho.

A análise do índice de área foliar das plantas alvo de algodão mostrou valor de IAF 1,46, para plantas com 0,80 m e 54 DAE, e de 10,3 para plantas com 1,0 m e 90 DAE. Este segundo valor encontra-se acima dos encontrados como média na literatura (Heitholt et al., 1992; Heitholt, 1994), entretanto, isto pode ser explicado pelo fato das plantas analisadas terem sido selecionadas como as maiores e mais enfolhadas, com o propósito de dificultar a penetração das gotas, não representando assim a média das plantas existentes. 
Tabela 7. Área foliar das plantas de algodoeiro aos 54 DAE, com altura de 0,80 $\mathrm{m}$, utilizadas como alvo na avaliação da penetração das gotas de pulverização (ltuverava-SP, 2004).

\begin{tabular}{ccccc}
\hline Planta & \multicolumn{4}{c}{ Área foliar $\left(\mathrm{cm}^{2}\right)$} \\
& Repetição 1 & Repetição 2 & Repetição 3 & Repetição 4 \\
\hline 01 & 1734,94 & 2358,26 & 1059,40 & 2099,21 \\
02 & 1574,33 & 1899,28 & 1525,16 & 1489,82 \\
03 & 2122,47 & 1643,97 & 1244,82 & 1294,68 \\
04 & 2098,26 & 1203,43 & 1501,52 & 1687,98 \\
05 & 1791,86 & 1759,30 & 1606,79 & 1993,79 \\
06 & 2429,38 & 2176,29 & 1739,33 & 1641,94 \\
Média & 1958,54 & 1840,09 & 1446,17 & 1701,24 \\
\hline
\end{tabular}

Tabela 8. Área foliar das plantas de algodoeiro aos 90 DAE, com altura de 1,00 $\mathrm{m}$, utilizadas como alvo na avaliação da penetração das gotas de pulverização (Ituverava-SP, 2004).

\begin{tabular}{ccccc}
\hline Planta & \multicolumn{4}{c}{ Área foliar $\left(\mathrm{cm}^{2}\right)$} \\
& Repetição 1 & Repetição 2 & Repetição 3 & Repetição 4 \\
\hline 01 & 10731,03 & 14610,89 & 12094,27 & 10353,15 \\
02 & 10578,69 & 14053,04 & 10571,24 & 10991,59 \\
03 & 10904,52 & 12855,97 & 12984,24 & 15257,18 \\
04 & 11692,79 & 18423,72 & 11011,20 & 10962,49 \\
05 & 11910,63 & 9777,20 & 9451,51 & 9429,32 \\
06 & 9817,57 & 17926,91 & 9234,27 & 18161,22 \\
Média & 10939,21 & 14607,96 & 10891,12 & 12525,82 \\
\hline
\end{tabular}




\subsection{Avaliação do tamanho de gotas}

Uma avaliação visual prévia dos resultados do tamanho de gotas mostrou que nenhum dos tratamentos utilizados foi eficiente em colocar uma quantidade adequada de gotas sobre os papéis hidrossensiveis posicionados na parte inferior dos amostradores, razão pela qual os mesmos não foram considerados nas análises. A aplicação do teste de Hartley aos dados obtidos para os papéis posicionados na parte superior mostrou que as variâncias não eram homogêneas, razão pela qual os dados foram transformados por arc sen raiz (x/100), conforme o recomendado por Banzato \& Kronka (1989) para dados em porcentagem.

A análise de variância aplicada aos dados de tamanho de gotas chegando em diferentes posições do algodoeiro com $0,80 \mathrm{~m}$ de altura mostrouse significativa ao nivel de $1 \%$ de probabilidade pelo teste $\mathrm{F}$ para as interações diâmetro produzido $\mathrm{x}$ diâmetro coletado $\mathrm{e}$ posição na planta $\mathrm{x}$ diâmetro coletado, com média geral de $9,94 \%$ e coeficiente de variação (CV) de 41,67\%. Aplicando-se o teste de Tukey ao nível de $5 \%$ de probabilidade às médias da interação diâmetro produzido $x$ diâmetro coletado (Tabela 9) observa-se que, independente do tamanho de gotas produzido, gotas na faixa de tamanho entre 95 e $174 \mu \mathrm{m}$ foram mais eficientemente coletadas. Gotas com diâmetros entre 209 e $323 \mu \mathrm{m}$ apresentaram características intermediárias enquanto que gotas com diâmetro superior a $363 \mu \mathrm{m}$ não diferiram dos piores resultados. Também para gotas na faixa de 95 e $174 \mu \mathrm{m}$, quanto maior o diâmetro produzido menor a porcentagem de gotas coletadas, o que pode ser explicado pela menor quantidade de gotas finas produzidas por pontas com pulverizações mais grossas. Para gotas com diâmetro superior a 209 m, a elevação do diâmetro de gotas produzido não representou uma elevação na porcentagem de gotas coletadas. 
Tabela 9. Teste de Tukey ao nível de $5 \%$ de probabilidade aplicado às médias da interação diâmetro produzido $x$ diâmetro coletado, para a página superior da folha de plantas de algodoeiro com $0,80 \mathrm{~m}$ (ItuveravaSP, 2004).

\section{Diâmetro produzido $(\mu \mathrm{m})$}

Diâmetro

Coletado

200

243

297

358

396

$(\mu \mathrm{m}) \quad$ Porcentagem do número de gotas sobre a amostra ${ }^{(1)}$

\begin{tabular}{lllrlrlllll}
\hline 95 & 34,27 & Aa & 26,33 & Ba & 20,85 & Cbc & 22,35 & BCab & 22,26 & Bcab \\
137 & 28,50 & Ab & 27,59 & Aa & 25,81 & Aab & 26,85 & Aa & 25,83 & Aa \\
174 & 27,24 & Abb & 27,86 & Aba & 29,72 & Aa & 23,97 & Ba & 24,17 & Ba \\
209 & 16,97 & Ac & 19,88 & Ab & 19,66 & Ac & 18,09 & Abc & 19,04 & Abc \\
242 & 14,13 & Acd & 15,94 & Abc & 16,01 & Acd & 15,80 & Acd & 15,28 & Acd \\
282 & 10,48 & Ade & 11,73 & Acd & 12,30 & Ade & 12,69 & Ade & 14,32 & Acd \\
323 & 7,78 & Aef & 7,76 & Ade & 9,21 & Aef & 8,75 & Aef & 11,97 & Ad \\
363 & 5,97 & Aefg & 5,66 & Aef & 6,17 & Afg & 6,43 & Afg & 6,67 & Afg \\
403 & 5,25 & Afgh & 5,08 & Aef & 5,99 & Afgh & 7,66 & Aef & 5,47 & Afg \\
444 & 4,71 & ABfgh & 3,49 & Bef & 6,02 & ABfgh & 6,94 & ABfg & 8,87 & Aef \\
484 & 2,66 & Afgh & 3,77 & Aef & 4,57 & Afgh & 6,00 & Afg & 5,88 & Afg \\
525 & 1,79 & Agh & 2,25 & Af & 2,45 & Agh & 5,48 & Afg & 4,62 & Afg \\
565 & 1,42 & Agh & 1,67 & Af & 1,18 & Agh & 3,85 & Afg & 4,36 & Afg \\
605 & 0,81 & Ah & 1,19 & Af & 0,97 & Ah & 2,38 & Ag & 3,34 & Ag \\
646 & 0,83 & Ah & 0,96 & Af & 1,05 & Agh & 2,32 & Ag & 2,24 & Ag \\
686 & 0,83 & Ah & 1,01 & Af & 1,05 & Agh & 2,02 & Ag & 2,74 & Ag \\
726 & 1,01 & Agh & 1,01 & Af & 1,01 & Ah & 1,87 & Ag & 1,94 & Ag \\
\hline
\end{tabular}

DMS (DPdDC): 4.22

DMS(DCdDP): 5.13

(1) Dados transformados por arc sen raiz $(x / 100)$.

Médias seguidas por uma mesma letra maiúscula na linha e minúscula na coluna não diferem entre si pelo teste de Tukey ao nível de $5 \%$ de probabilidade. 
O teste de Tukey ao nivel de $5 \%$ de probabilidade aplicado às médias da interação posição na planta $x$ diâmetro coletado (Tabela 10) mostrou que gotas entre 95 e $174 \mu \mathrm{m}$, além de chegarem em maior quantidade, atingiram de forma homogênea todas as partes da planta. Gotas com diâmetro entre 323 e $525 \mu \mathrm{m}$ chegaram de forma uniforme na ponta e meio, entretanto, foram ineficientes em atingir a região da saia. Gotas com diâmetro de $565 \mu \mathrm{m}$ ou superior não foram eficientemente captadas pelo alvo. 
Tabela 10. Teste de Tukey ao nível de $5 \%$ de probabilidade aplicado às médias da interação posição na planta $x$ diâmetro coletado, para a página superior da folha de plantas de algodoeiro com $0,80 \mathrm{~m}$ (ItuveravaSP, 2004).

\begin{tabular}{|c|c|c|c|c|}
\hline \multirow{3}{*}{$\begin{array}{c}\text { Diâmetro } \\
\text { Coletado } \\
\qquad(\mu \mathrm{m})\end{array}$} & \multicolumn{4}{|c|}{ Posição na planta } \\
\hline & Superior & Médio & \multicolumn{2}{|c|}{ Inferior } \\
\hline & \multicolumn{4}{|c|}{ Porcentagem do número de gotas sobre a amostra ${ }^{(1)}$} \\
\hline 95 & $21,99 \mathrm{Bb}$ & $24,55 \mathrm{Ba}$ & 29,10 & $\mathrm{Aa}$ \\
\hline 137 & $26,57 \mathrm{Aa}$ & $27,48 \mathrm{Aa}$ & 26,71 & $\mathrm{Aa}$ \\
\hline 174 & $27,17 \mathrm{Aa}$ & $26,90 \mathrm{Aa}$ & 25,70 & $\mathrm{Aa}$ \\
\hline 209 & 19,63 Abc & $19,07 \mathrm{Ab}$ & 17,48 & $A b$ \\
\hline 242 & 16,95 Acd & $16,08 \mathrm{Ab}$ & 13,27 & $\mathrm{Bc}$ \\
\hline 282 & 13,80 Ade & $12,03 \mathrm{AC}$ & 11,10 & Acd \\
\hline 323 & 10,65 Aef & $8,78 \mathrm{Bcd}$ & 7,84 & $\mathrm{Bd}$ \\
\hline 363 & 8,64 Afg & 6,48 Ade & 3,42 & $\mathrm{Be}$ \\
\hline 403 & $8,57 \mathrm{Afg}$ & 6,88 Ade & 2,22 & $\mathrm{Be}$ \\
\hline 444 & 7,89 Afg & 6,75 Ade & 3,37 & $\mathrm{Be}$ \\
\hline 484 & 6,46 Agh & 5,11 Adef & 2,16 & $\mathrm{Be}$ \\
\hline 525 & 5,14 Aghi & 2,95 ABefg & 1,86 & $\mathrm{Be}$ \\
\hline 565 & 3,75 Ahi & 2,49 Afg & 1,26 & $\mathrm{Ae}$ \\
\hline 605 & 2,77 Ahi & $1,46 \mathrm{Afg}$ & 0,99 & $\mathrm{Ae}$ \\
\hline 646 & 2,55 Ahi & $0,97 \mathrm{Ag}$ & 0,92 & $\mathrm{Ae}$ \\
\hline 686 & $2,24 \mathrm{Ai}$ & 1,43 Afg & 0,92 & $\mathrm{Ae}$ \\
\hline 726 & $2,08 \quad \mathrm{Ai}$ & $1,01 \mathrm{Ag}$ & 1,01 & $\mathrm{Ae}$ \\
\hline
\end{tabular}

DMS(PdD): 2.81

(1) Dados transformados por arc sen raiz $(x / 100)$

Médias seguidas por uma mesma letra maiúscula na linha e minúscula na coluna não diferem entre si pelo teste de Tukey ao nível de $5 \%$ de probabilidade. 
A análise de variância aplicada aos dados de tamanho de gotas chegando em diferentes posições do algodoeiro com 1,0 m de altura, assim como para $0,80 \mathrm{~m}$, mostrou-se significativa ao nivel de $1 \%$ de probabilidade pelo teste $F$ para as interações diâmetro produzido $x$ diâmetro coletado $\mathrm{e}$ posição na planta $x$ diâmetro coletado, com média geral de $9,80 \%$ e coeficiente de variação (CV) de 44,37\%. Aplicando-se o teste de Tukey ao nivel de $5 \%$ de probabilidade às médias da interação diâmetro produzido $x$ diâmetro coletado (Tabela 11) observa-se que, independente do tamanho de gotas produzido, gotas na faixa de tamanho entre 95 e $174 \mu \mathrm{m}$ foram mais eficientemente coletadas, exceto para $396 \mu \mathrm{m}$, onde a faixa esteve entre 95 e $209 \mu \mathrm{m}$. Gotas com diâmetros entre 209 e $282 \mu \mathrm{m}$ apresentaram características intermediárias enquanto que gotas com diâmetro superior a $323 \mu \mathrm{m}$ tenderam a não diferir dos piores resultados. Para gotas na faixa de 95 e $174 \mu \mathrm{m}$, assim como o observado para plantas com $0,80 \mathrm{~m}$, quanto maior o diâmetro produzido menor a porcentagem de gotas coletadas. Para gotas com diâmetro entre 282 e 363 $\mu \mathrm{m}$ a porcentagem aumentou com o tamanho das gotas produzido, enquanto que para os superiores a $403 \mu \mathrm{m}$, a elevação do diâmetro de gotas produzido não representou uma elevação na porcentagem de gotas coletadas. 
Tabela 11. Teste de Tukey ao nível de $5 \%$ de probabilidade aplicado às médias da interação diâmetro produzido $x$ diâmetro coletado, para a página superior da folha de para plantas de algodoeiro com $1,00 \mathrm{~m}$ (Ituverava-SP, 2004).

\begin{tabular}{|c|c|c|c|c|c|c|c|c|c|c|}
\hline \multicolumn{11}{|c|}{ Diâmetro produzido $(\mu \mathrm{m})$} \\
\hline \multirow{3}{*}{$\begin{array}{l}\text { Diâmetro } \\
\text { Coletado } \\
\qquad(\mu \mathrm{m})\end{array}$} & \multirow{2}{*}{\multicolumn{2}{|c|}{200}} & \multirow{2}{*}{\multicolumn{2}{|c|}{243}} & \multirow{2}{*}{\multicolumn{2}{|c|}{297}} & \multirow{2}{*}{\multicolumn{2}{|c|}{358}} & \multirow{2}{*}{\multicolumn{2}{|c|}{396}} \\
\hline & & & & & & & & & & \\
\hline & \multicolumn{10}{|c|}{ Porcentagem do número de gotas sobre a amostra ${ }^{(1)}$} \\
\hline 95 & 30,58 & $\mathrm{Aa}$ & 26,21 & $\mathrm{Aba}$ & 22,55 & Bcab & 19,89 & CDbcd & 17,78 & $\mathrm{Dbc}$ \\
\hline 137 & 28,44 & $\mathrm{Aa}$ & 27,87 & $\mathrm{Aa}$ & 24,99 & Aba & 25,16 & ABab & 23,03 & Bab \\
\hline 174 & 29,05 & $\mathrm{Aa}$ & 27,67 & Aba & 27,21 & Aba & 25,39 & Aba & 23,71 & $\mathrm{Ba}$ \\
\hline 209 & 19,83 & $\mathrm{ABb}$ & 17,59 & $\mathrm{Bb}$ & 19,25 & Abbc & 20,43 & ABabc & 23,17 & $\mathrm{Aa}$ \\
\hline 242 & 16,39 & $A b$ & 15,73 & Abc & 15,82 & Acd & 18,08 & Acd & 16,41 & Ac \\
\hline 282 & 9,96 & $\mathrm{BC}$ & 12,01 & Abcd & 13,72 & Abde & 14,88 & Ade & 15,22 & Acd \\
\hline 323 & 5,86 & $\mathrm{Bcd}$ & 7,90 & Abde & 9,70 & Abef & 10,73 & Aef & 10,13 & $A b d$ \\
\hline 363 & 3,24 & $\mathrm{Bd}$ & 5,22 & Abef & 6,53 & Abfg & 6,73 & $A B f g$ & 8,40 & Aef \\
\hline 403 & 3,17 & $\mathrm{Ad}$ & 4,87 & Aef & 4,51 & Afgh & 6,88 & Afg & 6,05 & Aefg \\
\hline 444 & 3,10 & $\mathrm{Ad}$ & 5,14 & Aef & 3,57 & Agh & 5,85 & Afg & 6,85 & Aefg \\
\hline 484 & 2,06 & $\mathrm{Ad}$ & 3,42 & Aef & 2,83 & Agh & 6,45 & Afg & 3,57 & Afg \\
\hline 525 & 1,78 & $\mathrm{Ad}$ & 2,32 & Af & 2,45 & Agh & 4,08 & $\mathrm{Ag}$ & 3,21 & Afg \\
\hline 565 & 1,45 & $\mathrm{Ad}$ & 2,30 & Af & 2,11 & Agh & 3,59 & $\mathrm{Ag}$ & 3,91 & Afg \\
\hline 605 & 1,19 & $\mathrm{Ad}$ & 1,75 & Af & 1,62 & Agh & 2,98 & $\mathrm{Ag}$ & 2,69 & $\mathrm{Ag}$ \\
\hline 646 & 0,83 & $\mathrm{Ad}$ & 1,67 & Af & 1,15 & Agh & 2,48 & $\mathrm{Ag}$ & 3,15 & Afg \\
\hline 686 & 1,01 & $\mathrm{Ad}$ & 1,15 & $A f$ & 0,89 & $A h$ & 2,38 & $\mathrm{Ag}$ & 3,03 & Afg \\
\hline 726 & 1,01 & Ad & 0,83 & Af & 0,89 & Ah & 2,12 & $\mathrm{Ag}$ & 2,10 & $\mathrm{Ag}$ \\
\hline
\end{tabular}

DMS (DPdDC): 4.43 DMS(DCdDP): 5.38

(1) Dados transformados por arc sen raiz $(x / 100)$

Médias seguidas por uma mesma letra maiúscula na linha e minúscula na coluna não diferem entre si pelo teste de Tukey ao nível de $5 \%$ de probabilidade. 
O teste de Tukey ao nível de $5 \%$ de probabilidade aplicado às médias da interação posição na planta $x$ diâmetro coletado (Tabela 12) mostrou que gotas entre 95 e $174 \mu \mathrm{m}$ chegaram em maior quantidade e que as de até $209 \mu \mathrm{m}$ atingiram de forma homogênea todas as partes da planta. Gotas com diâmetro entre 242 e $363 \mu \mathrm{m}$ chegam de forma uniforme na ponta e meio, entretanto, são ineficientes em atingir a região da saia. Gotas com diâmetro entre 403 e $525 \mu \mathrm{m}$ atingiram somente a parte superior das plantas enquanto que as com diâmetro superior a $605 \mu \mathrm{m}$ não foram eficientemente captadas pelo alvo. 
Tabela 12. Teste de Tukey ao nível de $5 \%$ de probabilidade aplicado às médias da interação posição na planta $x$ diâmetro coletado, para a página superior da folha de plantas de algodoeiro com 1,00 m (ItuveravaSP, 2004).

\begin{tabular}{|c|c|c|c|c|c|c|}
\hline \multirow{3}{*}{$\begin{array}{c}\text { Diâmetro } \\
\text { Coletado } \\
(\mu \mathrm{m})\end{array}$} & \multicolumn{6}{|c|}{ Posição na planta } \\
\hline & \multicolumn{2}{|c|}{ Superior } & \multicolumn{2}{|c|}{ Médio } & \multicolumn{2}{|c|}{ Inferior } \\
\hline & \multicolumn{6}{|c|}{ Porcentagem do número de gotas sobre a amostra ${ }^{(1)}$} \\
\hline 95 & 21,07 & $\mathrm{Bb}$ & 22,78 & $\mathrm{Bbc}$ & 26,35 & $\mathrm{Aa}$ \\
\hline 137 & 25,43 & $\mathrm{Aa}$ & 26,02 & Aab & 26,24 & $\mathrm{Aa}$ \\
\hline 174 & 26,19 & $\mathrm{Aa}$ & 27,68 & $\mathrm{Aa}$ & 25,95 & $\mathrm{Aa}$ \\
\hline 209 & 20,53 & $\mathrm{Ab}$ & 21,12 & Ac & 18,51 & $A b$ \\
\hline 242 & 17,62 & Abc & 19,03 & Ac & 12,80 & $\mathrm{Bc}$ \\
\hline 282 & 14,81 & Acd & 13,56 & $A B d$ & 11,10 & $\mathrm{Bc}$ \\
\hline 323 & 10,91 & Ade & 8,84 & Abe & 6,84 & $\mathrm{Bd}$ \\
\hline 363 & 8,32 & Aef & 5,88 & ABef & 3,87 & Bde \\
\hline 403 & 8,40 & Aef & 4,13 & Bfg & 2,76 & Bde \\
\hline 444 & 8,63 & Aef & 3,40 & Bfg & 2,67 & Bde \\
\hline 484 & 6,98 & Aefg & 1,90 & $\mathrm{Bfg}$ & 2,11 & $\mathrm{Be}$ \\
\hline 525 & 5,67 & Afgh & 1,60 & $\mathrm{Bg}$ & 1,03 & $\mathrm{Be}$ \\
\hline 565 & 5,16 & Afgh & 1,29 & $\mathrm{Bg}$ & 1,57 & $\mathrm{Be}$ \\
\hline 605 & 3,88 & Agh & 1,24 & $\mathrm{Ag}$ & 1,01 & $\mathrm{Ae}$ \\
\hline 646 & 3,26 & Agh & 0,94 & $\mathrm{Ag}$ & 1,37 & $\mathrm{Ae}$ \\
\hline 686 & 2,70 & Ah & 1,01 & $\mathrm{Ag}$ & 1,37 & $\mathrm{Ae}$ \\
\hline 726 & 2,15 & $A h$ & 1,01 & $\mathrm{Ag}$ & 1,01 & $\mathrm{Ae}$ \\
\hline
\end{tabular}

DMS(PdD): 2.95 DMS(DdP): 4.17

(1) Dados transformados por arc sen raiz $(x / 100)$

Médias seguidas por uma mesma letra maiúscula na linha e minúscula na coluna não diferem entre si pelo teste de Tukey ao nível de $5 \%$ de probabilidade. 
Pela análise dos resultados verifica-se que as plantas de algodoeiro, assim como o esperado pelas afirmações de Matthews (1999) e Sumner (2000), agem como um filtro eficiente para gotas grossas, que tendem a ser depositadas preferencialmente nas superficies das folhas superiores. Nos ensaios, a semelhança estatística entre a quantidade de gotas grossas sobre os amostradores posicionados nos terços superior e inferior das plantas pode ser explicada pela baixa quantidade de gotas muito grossas (acima de $500 \mu \mathrm{m}$ ) produzidas pelas pontas utilizadas. Qualquer que seja a explicação, os resultados obtidos sugerem que gotas com diâmetro superior a $500 \mu \mathrm{m}$ não devem ser utilizadas no tratamento fitossanitário do algodoeiro em função da baixa penetração e alta probabilidade de escorrimento observada.

Em ambas as épocas, gotas com diâmetros na faixa de 95 a 174 $\mu \mathrm{m}$ se distribuíram melhor no perfil da planta do algodoeiro, caracterizando a melhor penetração proporcionada por gotas finas, concordando com as afirmações de Matthews (1982) e Matuo et al. (2003). Considerando-se a faixa de 100 a $170 \mu \mathrm{m}$, obtem-se gotas maiores que $100 \mu \mathrm{m}$, necessárias ao adequado controle da deriva (Matthews, 1992, 1999), com boa penetração e deposição na copa do algodoeiro. Assim, para pulverizações onde a distribuição de calda por toda a planta é necessária, a seleção de pontas que produzam a maior parte do espectro de gotas dentro dessa faixa de tamanho tende a proporcionar melhor eficácia no tratamento fitossanitário do algodoeiro com menores volumes de água. Para pulverizações onde o alvo é o terço médio e superior da planta, gotas de até $363 \mu \mathrm{m}$ poderão ser utilizadas e para o terço superior, gotas com até $525 \mu \mathrm{m}$. Entretanto, estudos complementares de cobertura e deposição de calda, com gotas dentro destas faixas de diâmetros, necessárias a eficácia do controle das principais pragas do algodoeiro, conforme o explicado por Himel (1969), Matthews (1992), Ozmeri \& Cilingir (1992), Carvalho \& Furlani Jr. (1997) e Matthews (1999), e a semelhança do realizado por Ferreira (2003) para a cultura de citros, são ainda necessários. 
Gotas com diâmetros superiores a $525 \mu \mathrm{m}$ não devem ser utilizadas no tratamento fitossanitário do algodoeiro. 


\section{CONCLUSÕES}

Pelos resultados obtidos nas condições dos ensaios, para as duas épocas analisadas, 54 e 90 dias após emergência e 0,80 e 1,00 metro de altura, respectivamente, pode-se concluir que:

1. Gotas com diâmetros na faixa de 95 a $174 \mu \mathrm{m}$ proporcionaram melhor distribuição no perfil da planta do algodoeiro, devendo ser a faixa utilizada como base da qualidade em pulverizações onde a distribuição de calda por toda a planta é necessária;

2. Em pulverizações onde o alvo é o terço médio e superior da planta, gotas de até $363 \mu \mathrm{m}$ mostraram-se eficientes;

3. Em pulverizações onde o alvo é o superior da planta, gotas de até 525 $\mu \mathrm{m}$ mostraram-se eficientes;

4. Gotas com diâmetro superior a $525 \mu \mathrm{m}$, em função da baixa penetração não devem ser utilizadas no tratamento fitossanitário do algodoeiro;

5. Apenas a variação nos diâmetros de gotas não possibilitou que as mesmas atingissem a página inferior das folhas em nenhuma parte do perfil da planta. Dessa forma, quando o alvo for a página inferior das plantas do algodoeiro, produtos de ação sistêmica ou translaminar 
deverão ser utilizados ou modificações no posicionamentos das pontas em relação a cultura deverão ser estudadas;

6. Estudos complementares de cobertura e deposição de calda, com gotas dentro destas faixas de diâmetros, necessárias a eficácia do controle das principais pragas do algodoeiro, são ainda necessários. 
ANEXO 
Anexo A - Rotina desenvolvida com base em LALLANA (1999) para análise da área foliar de plantas de algodoeiro. (Ituverava - 2004).

- Corel Photo-Paint

a Ferramentas/Opções/Geral

$>$ Unidade: centímetros

- Abrir imagem

口 Imagem/Modo de cor/preto e branco

$>$ Método de conversão: Linha artística

$>$ Intensidade: Ajustar para eliminar brancos da folha

- Complementar possíveis brancos com ferramenta pintura (pincel)

- Limpar com ferramenta borracha

- Imagem/Modo de cor/tons de cinza

- Arquivo/Propriedades do documento

> Anotar largura e altura em pixels e na unidade de medida ( $\mathrm{mm}, \mathrm{cm}$, pol, etc)

a Salvar arquivo no formato BMP

- Idrisi for Windows

a File/Import/Desktop/BMPIDRIS

- Selecionar arquivo

- Definir mesmo nome para saída

- Ok

ㄱ File/Export/Desktop/TIFIDRIS

- Input Idrisi Image: selecionar

- TIFF resolution: alterar se necessário

- Outup TIFF: definir mesmo nome input

- Ok

a File/Import/Desktop/TIFIDRIS

- Selecionar arquivo 
- Definir mesmo nome para saída

- Responder ok ao aviso de sobreposição

- Ok

* Calcular fator de correção:

$\mathrm{FC}=\mathrm{RAIZ}(\operatorname{larg} \mathrm{x}$ comp em $\mathrm{cm} / \operatorname{larg} . \mathrm{X}$ comp. em pixels)

- utilizar 8 casas após a vírgula

a File/Document

- Selecionar documento

- Ok

- Substituir "Unit distance" por FC

- Ok

- Analysis/Database Query/Area

- Input Image: selecionar

- Output format: tabular

- Calculate areas: square meters

- Ok

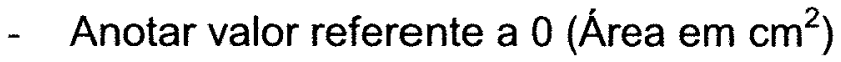

OBS: Antes de iniciar o Idrisi, certificar-se de que as unidades de data e número do computador estão no sistema inglês. 


\section{REFERÊNCIAS BIBLIOGRÁFICAS}

BANZATTO, D.A.; KRONKA, S.N. Experimentação agrícola. Jaboticabal: FUNEP, 1989. 247p.

BARNI, N.A.; BERGAMASCHI, H. Alguns princípios técnicos para a semeadura. In: MIYASAKA, S.; MEDINA, J.C. (Ed.). A soja no Brasil. Campinas: ITAL, 1981. p. 453-685.

BELTRÃO, N.E.M.; AZEVEDO, D.M.P. de; VIEIRA, D.J. et al. Observações morfológicas e agronômicas em algodoeiro arbóreo precoce. I. Frutograma de plantas da cultivar CNPA $4 \mathrm{M}$ de $5^{\circ}$ ano de ciclo. Campina Grande: Embrapa, CNPA, 1992. 6 p. (Embrapa. CNPA. Pesquisa em Andamento, 14).

BELTRÃO, N.E.M.; AZEVEDO, D.M.P. de; VIEIRA, D.J. et. al. Observações morfológicas e agronômicas em algodoeiro arbóreo precoce. II. Fluxograma de plantas da cultivar CNPA $5 \mathrm{M}$ de $1^{\circ}$ e $2^{\circ}$ anos de ciclo. Campina Grande: Embrapa, CNPA, 1993. 11 p. (Embrapa. CNPA. Pesquisa em Andamento, 36).

BELTRÃO, N.E.M.; SOUZA, J.G. de; GUERRA, J.S. et. al. Manejo cultural do algodoeiro herbáceo na região do cerrado. In: FARIAS, F.J.C.; AGUIAR, P.H.; FREIRE, E.C. et al. (Ed.). Mato Grosso: liderança e competitividade. Rondonópolis: Fundação MT, 1999. p. 70-86. (Fundação MT. Boletim, 3). 
BODE, L.C. Spray application tecnology. In: WHORTER, C.G.M; GEBHARDT, M.R. Methods of applying herbicides. West Clark: WSSA, 1987. cap. 6, p. 85-110.

BOLONHEZI, A.C.; JUSTI, M.M.; OLIVEIRA, R.C. de et al. Espaçamentos estreitos para variedades de algodão herbáceo: desenvolvimento da planta e retenção de estruturas reprodutivas. In: CONGRESSO BRASILEIRO DE ALGODÃO, 2., Ribeirão Preto, 1999. Resumos. Campina Grande: Embrapa, CNPA, 1999. p. 611-613.

BOUSE, F.L; CARLTON, J.B. Factors affecting size distribution of vegetable oil spray droplets. Transactions of the ASAE, v. 28, n. 4, p. 1068-1073, 1985.

BRASIL. Ministério da Agricultura. Companhia Nacional de Abastecimento. Avaliação da safra agrícola 2004/2005: terceiro levantamento. http://www.conab.gov.br/download/Safra/3levantamentoPlantio.doc (12 abr. 2005).

CARVALHO, W.P.A. de. Estudo comparativo entre métodos de amostragens de gotas para determinação de faixa de deposição nas aplicações de produtos líquidos. Botucatu, 1995. 64 p. Dissertação (Mestrado) - Faculdade de Ciências Agronômicas, Universidade Estadual Paulista "Júlio de Mesquita Filho".

CARVALHO, W.P.A.; FURLANI JUNIOR, J.A. Estudo comparativo entre coletores para determinação do DMV e coeficiente de dispersão na atmosfera de gotas em aplicações de produtos líquidos. Revista Energia na Agricultura, v.12, n.1, p.29-38, 1997. 
CHAIM, A.; CASTRO, V.L.; CORRALES, F. et al. Método para monitorar perdas na aplicação de agrotóxicos na cultura do tomate. Pesquisa Agropecuária Brasileira, v.34, n.5, p.741-747, 1999.

CHAIM, A.; PESSOA, M.C.P.Y.; CAMARGO NETO, J. et al. Comparison of microscopic method and computational program for pesticide deposition evaluation of spraying. Pesquisa Agropecuária Brasileira, v.37, n.4, p.439496, 2002.

CHIAVEGATO, E.J. Efeito do ambiente e de cultivares nos componentes de produção e nas características tecnológicas da fibra e do fio de algodão. Piracicaba, 1995. 115p. Tese (Doutorado) - Escola Superior de Agricultura "Luiz de Queiroz", Universidade de São Paulo.

CIA, E.; FUZATTO, M. G. Manejo de doenças na cultura do algodão. In: CIA, E.; FREIRE, E.C.; SANTOS, W.J. (Ed.). Cultura do algodoeiro. Piracicaba: Potafós, 1999. p.121-131.

CUNHA, J.P.R.; TEIXEIRA, M.M. Escolha de bico para pulverização. Cultivar Máquinas, v.3, n.18, p.8-11, 2003

EMPRESA BRASILEIRA DE PESQUISA AGROPECUÁRIA. Cultivo do algodão irrigado - Algodão. http://sistemasdeprodução.cnptia.embrapa.br/ (12 abr. 2005).

FAO. Equipo de aplicación de pesticida para uso en agricultura. Roma: FAO, 1996. v.2: Equipo impulsado mecánicamente, 150 p. (Boletin de Servicios Agricolas de la FAO112/2). 
FAO. Agricultural pesticide sprayers. Roma: FAO, 1998. v,2 63 p. (FAO technical standards: sprayer specifications and test procedures).

FAO BULLETIN OF STATISTICS, v.1, n.2, p.72-73, 2000.

FERREIRA, M.C. Caracterização da cobertura de pulverização necessária para controle do ácaro Brevipalpus phoenicis (G., 1939) em citros. Jaboticabal, 2003. 64p. Tese (Doutorado) - Faculdade de Ciências Agrárias e Veterinárias, Universidade Estadual Paulista "Júlio de Mesquita Filho".

FNP CONSULTORIA \& COMERCIO. AGRIANUAL 2000: anuário de agricultura brasileira, São Paulo, 2000. p.152-167: Algodão.

FNP CONSULTORIA \& COMERCIO. AGRIANUAL 2002: anuário de agricultura brasileira, São Paulo, 2002. p.141-154: Algodão.

FNP CONSULTORIA \& COMERCIO. AGRIANUAL 2005: anuário de agricultura brasileira, São Paulo, 2005. p.181-198: Algodão.

FOX, R.D; DERKSEN R.C; COOPER, J.A. et. al. Visual and image system measurement of spray deposits using water-sensitive paper. Transactions of the ASAE, v.19, n.5, p.549-552, 2003.

FRANZ, E. Spray coverage analysis using a hand-held scanner. Transaction of the ASAE, v.36, n.5, p.1271-1278, 1993.

GASSEN, D. Aplicação sem erros. Cultivar Grandes Culturas. v.5, n.48, p.3031,2003 
GONDIM, D.M.C.; BELOT, J.L.; SILVIE, P. et al. Manual de identificação das pragas, doenças, deficiências minerais e injúrias do algodoeiro no Brasil. 3.ed. Cascavel: COODETEC, 1999. 9p. (Boletim Técnico, 33).

HEITHOLT, J.J. Canopy characteristics associated with deficient and escessive cotton plant population densities. Crop Sciense, v.34, p.1291-1297, 1994.

HEITHOLT, J.J.; PETTIGREW, W.T.; MERIDITH JÚNIOR, W.R. Light interception and lint yield of narrow-row cotton. Crop Sciense v.32, p.728733, 1992.

HIMEL, C.M. The optimum size for insecticide spray droplets. Journal of Economic Entomology, v.62, n.4, p.919-925, 1969.

HIMEL, C.M.; MORE, A.D. Spray droplet size in control of spruce budworm, boll weevil, bollworm, and cabbage looper. Journal of Economic Entomology, v.62, n.4, p.916-918, 1969.

JIANG, G.; DERKSEN, R.C. Morphological image processing for spray deposit analysis. Transactions of the ASAE, v.38, n.5, p.1581-1591, 1995

LALLANA, V.H.; Medición del área foliar mediante escáner y software idrisi. FAVE, v.13, n.2, p.27-33, 1999.

LLOYD, E.P.; MCMEANS, J.J.; MERKL, M.E. Preferred feeding and egg layiang sites of the boll weevil and the effect of weevil damage on cotton plant. Journal of Economic Entomology, v.54, n.5, p.979-987, 1961. 
KIRKPATRICK, T.L.; ROTHROCK, C.S.; ALLEN, S.J. et. al. Compendium of cotton diseases. 2.ed. St. Paul: The American Phytopathological Society. 2001. $98 \mathrm{p}$.

MATTHEWS, G.A. Chemicals and equipment. PANS, v.21, n.2, p.213-225, 1975.

MATTHEWS, G.A. Pesticide application methods. London: Longman, 1979. $334 \mathrm{p}$.

MATHEWS, G.A. Pesticide applications methods. 2.ed. Singapore: Longman, 1992. 405p.

MATTHEWS, G.A. Application of pesticides to crops. Danvers: ICP, 1999. cap. 5, p. 127-157: Cotton and other arable row crops.

MATUO, T. Técnicas de aplicação de defensivos agricolas. Jaboticabal: Funep, 1990. 139p.

MATUO, T.; PIO, L.C.; RAMOS, H.H. et al. Tecnologia de aplicação dos agroquímicos e equipamentos (compact disc). In: ASSOCIAÇÃO BRASILEIRA DE EDUCAÇÃO AGRÍCOLA SUPERIOR. Curso de especialização por tutoria a distância: módulo de proteção de plantas. Brasilia, 2003.

MACDONALD, T; CHEN Y.R. Application of morphological image processing in agriculture. Transactions of the ASAE, v.33, n.4, p.1345-1351, 1990. 
MDM SEMENTES DE ALGODÃO; DELTA AND PINE LAND COMPANY. Guia técnico das cultivares de algodão. Uberlândia, s.d. 32p.

MONTEIRO, J.E.B.A. Microclima e ocorrência de ramulose no algodoeiro em diferentes densidades populacionais. Piracicaba, 2002. 99p. Dissertação (Mestrado) - Escola Superior de Agricultura "Luiz de Queiroz", Universidade de São Paulo.

NORDBO, E. Effects of nozzle size, travel speed and air assistance on deposition on artificial vertical and horizontal targets in laboratory experiments. Crop Protection, v.11, p.272-278. June 1992.

OZMERI, A; CILINGIR, I. Use of colorimetric technique in determining surface coverage in spraying. Agricultural Mechanization in Asia, Africa and Latin America, v.23, n.1, p.37-38, 1992.

OOSTERHUIS, D.M. Growth and development of a cotton plant. In: CIA, E.; FREIRE, E.C.; SANTOS, W.J. dos (Ed.). Cultura do algodoeiro. Piracicaba: POTAFOS, 1999. p. 35-55.

ORNELLAS, A,P.; HIROMOTO, D.M.; YUYAMA, M.M. et al. (Ed.) Boletim de pesquisa de algodão. Rondonópolis: Fundação MT, 2001. 238p. (Fundação MT. Boletim, 4).

PIO, L.C. Tecnologia de aplicação de produtos fitossanitários com pulverizadores terrestres. In: FANCELLI, A.L.; DOURADO NETO, D. (Ed.). Feijão irrigado: tecnologia e produtividade. Piracicaba: ESALQ, Depto. Produção Vegetal, 2003. p. 41-48. 
RAETANO, C.G.; SCUDELER, F.; BAUER, F.C. et al. Avaliação da cobertura de pulverização com diferentes equipamentos e condições operacionais na cultura do café. In: SIMPÓSIO INTERNACIONAL DE TECNOLOGIA DE APLICAÇÃO DE AGROTÓXICOS, 2., Jundiaí, 2001. Resumos. http://www.iac.br./ cma/sintag (18 dez. 2002).

RAMALHO, F.S.; JESUS, F.M.M. Distribuition of boll weevil (Anthonomus grandis Boheman) eggs within cotton plants. Tropical Agriculture, v.65, n.3, p.245-248, 1988.

RAMOS, H.H.; PIO, L.C. Tecnologia de aplicação de produtos fitossanitários. In: CURSO PARA FORMAÇÃO DE TÉCNICOS-INSTRUTORES COM CAPACITAÇÃO PARA O ENSINO DA APLICAÇÃO E MANUSEIO DE PRODUTOS FITOSSANITÁRIOS, São Paulo, 2000. São Paulo: Convênio ANDEF; FAESP; SENAR-SP, 2000. p.68-119.

RAMOS, H.H. Deriva de agroquímicos. Cultivar Máquinas, v.1, n.6, p.16-19, 2001

RAMOS, H.H. Bicos para a pulverização. Cultivar Máquinas, v.3, n.21, p.1619,2003

RAMOS, H.H.; ARAÚJJO, D.; LIMA, J.D.C.V. et al. Acurácia de um programa de computador na determinação de parâmetros da pulverização sobre papéis hidrossensiveis. In: SIMPÓSIO INTERNACIONAL DE TECNOLOGIA DE APLICAÇÃO DE AGROTÓXICOS, 3., Botucatu, 2004. Anais: Botucatu: FEPAF, 2004. p.1-4. 
REICHARD, D.L; ZHU, H; FOX, R.D. et. al. Computer simulation of variables that influence spray drift. Transactions of the ASAE, v.35, p.1401-1407, 1992.

ROSOLEM, C.A. Ecofisiologia e manejo da cultura do algodoeiro. Rondonópolis: Fundação MT, 2001. p. 147-160. (Fundação MT. Boletim, 4).

SAAB, O.J.G.A. Avaliação de um sistema de aplicação de defensivos utilizado em videiras no município de Londrina, PR. Botucatu, 1996. 65p. Dissertação (Mestrado) - Faculdade de Ciências Agronômicas, Universidade Estadual Paulista."Júlio de Mesquita Filho"

SANTOS, W.J. dos; SANTOS, K.B. dos; SANTOS, R.B. dos. Danos provocados por pulgões infectados com a virose mosaico das nervuras, nos diferentes estádios de crescimento de plantas da cultivar CNPA-ITA 90, suscetível e esta enfermidade (compact disc). In: CONGRESSO BRASILEIRO DE ALGODÃO, 4., Goiânia, 2003. Anais. Goiânia: EMBRAPA Algodão; Fundação GO, 2003.

SOARES, J.J.; LARA, F.M.; SILVA, C.A.D. et. al. Influência da posição do fruto na planta sobre produção do algodoeiro. Pesquisa Agropecuária Brasileira, v.34, n.5, p.755-759, 1999.

SISTLER, F.E.; SMITH, P.A.; RESTER, D.C. An image analyzer for aerial application patters. Transactions of the ASAE, v.25, p.885-887, 1982.

SUMNER, H.R.; HERZOG, G.A.; SUMNER, P.E. et. al. Chemical application equipment for improved deposition in cotton. The Journal of Cotton Science, v.4, n.1, p.19-27, 2000. 
SPRAYING SYSTEMS COMPANY. Planilha de dados técnicos sobre pontas de pulverização. Illinois, 1993. 1p.

TURNER, C.J.; HUNTINGTON, A.J. The use of a water sensitive dye for the detection and assessment of smal spray droplets. Journal of Agricultural Engineering Research, v.15, n.4, p.385-387, 1970.

VENDRAMIN, J.D.; NAKANO, O. Avaliação e danos de Aphis gossypii Glover, 1877 (Homóptera: Aphididae) no algodoeiro, cultivar IAC 17. Anais da Sociedade Entomológica do Brasil, v.10, n.1, p.89-96, 1981.

YATES, W.E; AKESSON, N.B; BAYER, D. Effects of the sprays adjuvants on drift hazards. Transactions of the ASAE, v.19, p.41-46, 1976.

YATES, W.E; AKESSON, N.B; COUTTS, H.H. Evaluation of drift residues from aerial applications. Transactions of the ASAE, v.9, p.389-397, 1966.

YATES, W.E; AKESSON, N.B; COWDEN, R.E. Criteria for minimizing drift residues on crops downwind from aerial applications. Transactions of the ASAE, v.17, n.4, p.627-632, 1974.

WOMAC, A.; ETHERIDGE, E.; SEIBERT, A. et. al. Sprayer speed and venturinozzle effects on broadcast application uniformity. Transactions of the ASAE, v.44, n.6 p.1437-1444, 2001.

ZHU, H; REICHARD, D.L; FOX, R.D. et. al. Simulation of drift of discrete sizes of water droplets from field sprayers. Transactions of the ASAE, v.37, n.5, p.1401-1407, 1994. 